\title{
Does the Incredible Years reduce child externalizing problems through improved parenting? The role of child negative affectivity and serotonin transporter linked polymorphic region (5-HTTLPR) genotype
}

\author{
JOYCE WEELAND, ${ }^{a, b}$ RABIA R. CHHANGUR,${ }^{a, b}$ SARA R. JAFFEE, ${ }^{c}$ DANIELLE VAN DER GIESSEN ${ }^{a}$ \\ WALTER MATTHYS, ${ }^{b}$ BRAM OROBIO DE CASTRO ${ }^{b}$ AND GEERTJAN OVERBEEK $^{a}$ \\ ${ }^{a}$ University of Amsterdam; ${ }^{b}$ Utrecht University; and ${ }^{c}$ University of Pennsylvania
}

\begin{abstract}
In a randomized controlled trial, the Observational Randomized Controlled Trial of Childhood Differential Susceptibility (ORCHIDS study), we tested whether observed parental affect and observed and reported parenting behavior are mechanisms of change underlying the effects of the behavioral parent training program the Incredible Years (IY). Furthermore, we tested whether some children are more susceptible to these change mechanisms because of their temperamental negative affectivity and/or serotonin transporter linked polymorphic region (5-HTTLPR) genotype. Participants were 387 Dutch children between 4 and 8 years of age $(M$ age $=6.31, S D=1.33 ; 55.3 \%$ boys $)$ and their parents. Results showed that although IY was successful in improving parenting behavior and increasing parental positive affect, these effects did not explain the significant decreases in child externalizing problems. We therefore found no evidence for changes in parenting behavior or parental affect being the putative mechanisms of IY effectiveness. Furthermore, intervention effects on child externalizing behavior were not moderated by child negative affectivity or 5-HTTLPR genotype. However, child 5-HTTLPR genotype did moderate intervention effects on negative parenting behavior. This suggests that in research on behavioral parent training programs, "what works for which parents" might also be an important question.
\end{abstract}

Parenting behavior, such as parenting strategies and parental affect, is one of the most robust predictors of early externalizing problems (for meta-analyses see Karreman, van Tuijl, van Aiken, \& Deković, 2006; Rothbaum \& Weisz, 1994) and has therefore been targeted in prevention and intervention programs among which are behavioral parent training (BPT; McCart, Priester, Davies, \& Azen, 2006). Although BPT has proven an effective method for decreasing children's externalizing problems, mean effect sizes are moderate (McCart et al., 2006; Menting, Orobio de Castro, \& Matthys, 2013). This might be explained by two things. First, we have limited insight into which specific mechanisms of change are responsible for the intervention effects ("what works") of BPT programs (for a review, see Forehand, Lafko, Parent, \& Burt, 2014). Second, these specific mechanisms may vary considerably between participating families ("what works for whom"; Leijten, Raaijmakers, Orobio de Castro, \& Matthys, 2013; Menting et al., 2013; Scott \& O'Connor, 2012). Gaining insight into what works for whom might help us tailor

This work was financially supported by the Netherlands Organization for Scientific Research (NWO: 452-10-005). We thank Loes Keijsers and Ellen Hamaker for their advice on the analyses performed for this manuscript.

Address correspondence and reprint requests to: Joyce Weeland, PO Box 15.804, Amsterdam 1001 NH, The Netherlands; E-mail: j.weeland@uva.nl.
BPT programs by indicating, for specific children or families, what is the needed, clinical focus, duration, and intensity, increasing their effectiveness (Chorpita, Becker, \& Daleiden, 2007).

Because BPT programs consist of multiple components, it is often unclear how specific mechanisms of change contribute to the intervention effects (for a review, see Forehand et al., 2014). Besides changes in the use of adequate parenting techniques, such as monitoring and giving specific praise, increases in parental positive affect (i.e., happiness and warmth) and decreases in parental negative affect (i.e., anger and harshness) may be important change mechanisms underlying the effectiveness of BPT programs (Coplan, Hastings, Lagacé-Séguin, \& Moulton, 2002; Duncombe, Havighurst, Holland, \& Frankling, 2012; Martin, Clements, \& Crnic, 2009). Furthermore, due to temperamental or genetic predispositions, these putative mechanisms of change might have a larger impact in some children than in others. Changes in parental affect might be particularly important change mechanisms for children who show heightened arousability and behavioral responses to others' emotions (i.e., heightened emotional reactivity). Specifically, temperamental negative affectivity and the serotonin transporter linked polymorphic region (5-HTTLPR) polymorphism have been previously related to such individual differences in emotional reactivity 
and might be related constructs (Auerbach et al., 1999; Belsky \& Pluess, 2009; Weeland, Slagt, et al., 2015). The current study tested whether intervention-induced changes in observed parental affect as well as observed and reported positive and negative parenting behavior mediated the effects of the BPT program the Incredible Years (IY) on parent-reported child externalizing problems. In addition, we tested whether some children are more susceptible to interventioninduced changes in parental affect and parenting behavior because of their temperamental negative affectivity and/or 5-HTTLPR genotype.

\section{What Works: Parental Affect and Parenting Behavior as Mechanisms of Change}

BPT teaches parents to use effective parenting behaviors in order to reduce child problem behaviors. Although the idea that BPT programs are effective in reducing child externalizing problems through parenting is strongly grounded in theory, studies testing parenting as a mediator of BPT effectiveness have yielded mixed results (Forehand et al., 2014; Gardner, Burton, \& Klimes, 2006; Hanisch, Hautmann, Plück, Eichelberger, \& Döpfner, 2014). A review of 16 intervention studies showed that, depending on the specific parenting behavior assessed, between $11 \%$ and $48 \%$ of tested mediators were significant (Forehand et al., 2014). Therefore, there has been a call for more research on the putative mediators of effective interventions (Forehand et al., 2014; Kazdin, 2007).

The focus of most studies on mediators of intervention effectiveness have been parenting behaviors such as monitoring, limit setting, and disciplinary techniques. However, besides actual changes in parenting behavior, BPT encourages parents to increase in warmth and positivity during interactions with their children. Equally as important as what parents do (i.e., parenting behavior) might be how they do it (i.e., expressed affect during parent-child interaction; Crandall, Deater-Deckard, \& Riley, 2015; Dix, 1991; Gardner et al., 2006; Rueger, Katz, Risser, \& Lovejoy, 2011). BPT programs might indirectly decrease children's externalizing problems, through increasing positive parental affect during parentchild interactions, and preventing coercive cycles set off by parental negative affect (for a review and meta-analysis see Kaminski, Valle, Filene, \& Boyle, 2008; Sandler, Schoenfelder, Wolchik, \& MacKinnon, 2011, but see also Hanisch et al., 2014). Previous longitudinal research even suggests that parental emotions are stronger predictors of child outcomes than actual parenting behavior itself (Duncombe et al., 2012; Isley, O'Neil, Clatfelter, \& Parke, 1999; Rudy $\&$ Grusec, 2006). For example, the detrimental effect of authoritarian parenting on children's self-esteem has been found to be explained by maternal negative emotions (Rudy \& Grusec, 2006). Changing parental affect seems to be a key mechanism in promoting desirable child behavior, preventing escalation of parental irritability, anger, and aggression, and breaking coercive interaction patterns within fami- lies in which children have high levels of externalizing problems (Isley et al., 1999; Rudy \& Grusec, 2006).

In addition, studies on mechanisms of change mostly look at a limited set of potential mediators, but they also have important methodological limitations. First, they mostly rely on parent reports of assessed mediators (parent behavior or affect) and outcomes (child behavior), which are likely to be biased as well as codependent. Second, BPT research often examines mediation by studying associations between an improvement in parenting behavior and a decrease in child externalizing problems at the same time point. These studies are therefore unable to conclude that change in parenting behavior preceded change in child externalizing problems. Failure to be able to take into account a timeline of change in the mediator and the outcome is seen as "the Achilles' heel of treatment studies" (Kazdin, 2007, p. 5). Therefore, in the current study we tested whether specific changes in observed parental affect and behavior at 6-month posttest mediated the intervention effect of IY on parent-reported externalizing problems at 10-month follow-up.

\section{What Works for Whom: Differential Effects by Child Temperament and Genotype}

Changes in parental affect and parenting behavior might not be equally important change mechanisms for all children. Children might differ in how strongly they react to others' emotions due to temperamental and genetic predispositions (Belsky \& Pluess, 2009; Weeland, Overbeek, Orobio de Castro, \& Matthys, 2015). There is some evidence these temperamental and genetic predispositions are related constructs (see Auerbach et al., 1999; Belsky \& Pluess, 2009, but see Dragan \& Oniszczenko, 2005; Auerbach, Ebstein, Kahana, \& Levine, 2001; Weeland, Slagt, et al., 2015). For example, both relate to individual differences in amygdala activity after exposure to expressed emotion (Kret, Denollet, Grèzes, \& de Gelder, 2011; Murphy et al., 2013). On the one hand, this might suggest that both temperamental and genetic differences in emotional reactivity are able to explain children's differential reactions to parenting and parenting interventions (i.e., emotional reactivity hypothesis). On the other hand, considering the mixed findings on their relatedness, as well as differences in how proximal they are to actual child behavior, it might be that one or the other moderates the impact of parenting and parenting interventions. The current study assessed whether the effects of changes in observed positive and negative parental affect and observed and reported parenting behavior on parent-reported child externalizing problems are moderated by child negative affectivity and/or 5HTTLPR genotype.

Children who show heightened emotional reactivity might become more aroused than less emotionally reactive children by others' emotions, might more easily alter their own mood, and might experience difficulties in regulating these emotions and their behavioral response (e.g., Auerbach et al., 1999; Davies \& Cicchetti, 2013; Gyurak et al., 2013; Hankin et al., 
2011; Murphy et al., 2013; but see Weeland, Slagt, et al., 2015). Thus, they may be more susceptible to (changes in) positive and negative emotions in the context of intervention (Scott \& O'Connor, 2012). At a behavioral level, such differences in emotional reactivity may be indexed by temperamental negative affectivity, defined as children's tendency to respond with high levels of negative affect such as anger or irritability to their environment (Derryberry \& Rothbart, 1988). Children's negative affectivity has been found to moderate the effects of parenting on child adjustment (Belsky, Hsieh, \& Crnic, 1998; Bradley \& Corwyn, 2008; Lipscomb et al., 2012; Morris et al., 2002; Ramos, Guerin, Gottfried, Bathurst, \& Oliver, 2005), as well as the effects of parenting interventions (Gallitto, 2015; Scott \& O'Connor, 2012; Van Zeijl et al., 2007). For example, maternal hostility has been found to predict child externalizing problems for children high on negative affectivity, but not for children low on this trait (Morris et al., 2002).

At a genetic level, emotional reactivity may be indexed by a polymorphism in the promoter region of the serotonin transporter gene (i.e., 5-HTTLPR). The 5-HTTLPR polymorphism, which has a high activity long allele and a low activity short allele, regulates serotonin availability, which is an important modulator of neural circuitry controlling behavioral and physiological processes including mood. Children's 5-HTTLPR genotype has been found to moderate the effects of parenting on child adjustment (i.e., Gene $\times$ Environment interactions; van IJzendoorn, Belsky, \& Bakermans-Kranenburg, 2012), as well as the effects of parenting programs (i.e., Gene $\times$ Intervention interactions; Albert et al., 2015; Bakermans-Kranenburg, van IJzendoorn, Pijlman, Mesman, \& Juffer, 2008; Van den Hoofdakker et al., 2012). For example, Hankin et al. (2011) found that children who carried a 5HTTLPR short allele (short-short [SS] and short-long [SL] genotypes) showed more positive affect when their parents were supportive and positive (observed, as well as measured by parent and child report), but less positive affect when their parents were nonsupportive and negative, compared to children carrying two long alleles (LL genotypes).

\section{The Current Study}

The current study features a randomized controlled trial (i.e., pretest, posttest, and follow-up) of IY among 387 parents and their children aged 4 to 8 years. We examined (a) whether changes in observed parental affect and observed and reported parenting behavior explained the effects of IY on decreases in parent-reported children's externalizing problems, and (b) whether some children were more susceptible to changes in parental affect and parenting behaviors based on their temperamental negative affectivity and/or 5-HTTLPR genotype. Specifically, we hypothesized that observed parental affect and parenting behavior at posttest would mediate the effect of IY on decreasing parent-reported child externalizing problems at follow-up. In addition, based on an emotional reactivity hypothesis, we expected that these change processes would be more strongly associated with reductions in externalizing problems in children high on negative affectivity or carrying one or two 5-HTTLPR short alleles. Specifically, these children were hypothesized to be more susceptible to intervention-induced changes in parental affect and parenting behavior and consequently show stronger decreases in externalizing problems after the intervention than children without these susceptibility characteristics.

\section{Methods and Materials}

\section{Participants}

Participating parent-child dyads $(N=387)$ were part of the longitudinal Observational Randomized Controlled Trial of Childhood Differential Susceptibility (ORCHIDS study; for details on a priori hypotheses, design, recruitment, and sample, see Chhangur, Weeland, Overbeek, Matthys, \& Orobio de Castro, 2012; Weeland et al., 2017). Children were between 4 and 8 years of age at the start of the study ( $M$ age $=6.31, S D=1.33)$, mostly born in The Netherlands (97.4\%), and $55.3 \%$ male. Parents (91\% were mothers) were between 23 and 51 years of age $(M$ age $=38.10, S D$ $=4.84$ ), over $80 \%$ born in the Netherlands, and about half of them $(47.8 \%)$ were higher educated (i.e., completed higher vocational training or university educational tracks).

\section{Procedure}

Parent-child dyads were recruited in two cohorts through two regional health care organizations. All families with children between the ages of 4 and 8 years living in the targeted municipalities received a personalized invitation letter including the questionnaire used for screening (i.e., the Eyberg Child Behavior Inventory; Eyberg, \& Pincus, 1999). Families with children scoring at or above the 75 th percentile of their respective cohort were invited for further participation. Parents signed written informed consent for participation of both themselves and their child. Participation in the randomized controlled trial (RCT) consisted of three measurement waves (i.e., pretest, posttest after 6 months, and follow-up after 10 months). During all measurement waves, data on parent and child behavior were collected through online questionnaires filled out by parents, as well as through observation during a structured play situation. Families were visited at home by one of the researchers or a trained research assistant. During the first home visit, saliva swabs were collected from children. After the first home visit, participants were randomly assigned to either the control group or the intervention group (50/50). See online-only supplementary Figure S.7 for an illustration of the participant flow.

The intervention group received the IY parent training between the pretest and the posttest. The control group did not receive intervention through the RCT, but was free to actively seek other (mental) health care during the study (i.e., "care as usual"). Approval for this study was received from the insti- 
tutional review board in Utrecht (METC UMC Utrecht, protocol number 11-320/K). For more information on the procedure see Chhangur et al. (2012) and Weeland et al. (2017).

\section{Intervention: The IY BASIC program}

The IY (Webster-Stratton, 2008) aims to prevent and intervene in the development of child externalizing problems by reducing harsh and unresponsive parenting and increasing positive and warm parenting. The program has been studied intensely and has been found effective in reducing child externalizing problems across settings and target populations (Menting et al., 2013). The program starts with a focus on positive parenting behavior such as play, praise, and incentives before discussing effective limit setting, ignoring unwanted behavior, and using time out strategies (Webster-Stratton, 2008). Discussion of these topics includes a focus on parent behavior as well as child and parent thoughts and emotions. IY is a group behavioral parent training consisting of 15 sessions (i.e., 14 weekly 2-hr sessions and a "booster" session). Groups were led by two group leaders with a background in clinical child psychology. The main leader was officially certified as a group leader by conducting at least two complete sets of the program and sending in at least one DVD session for review by a certified IY Trainer (through the Incredible Years Inc.). To ensure and monitor implementation fidelity, all leaders completed a weekly session-specific checklist. These checklists showed that, on average, $86 \%$ of session activities (e.g., brainstorms and role-plays) were executed by trainers and on average six vignettes were shown. It has been argued that positive intervention effects are obtained when the level of program integrity exceeds 60\% (Durlak \& DuPre, 2008). Participating parents attended 8.6 sessions on average. Of all parents randomized to the intervention condition, $44 \mathrm{did}$ not attend any sessions. These parents did not differ from parents who did attend sessions (see Weeland et al., 2017).

\section{Observation measures}

Parent and child were videotaped for 20 min at pretest, posttest, and follow-up. The observation procedure consisted of four 5-min periods in which parents and children played with a fixed set of toys: free play (i.e., to get used to being videotaped); child-directed play (i.e., child picked a toy and directed the session); parent-directed play (i.e., parent picked a toy and directed the session); and clean-up (i.e., parent had to make the child clean up the toys). The observational videos were coded by trained research assistants who were not involved in the study and who were blind to condition and measurement wave. Monthly calibration meetings were held to prevent observer drift. To provide estimates of interrater reliability (intraclass correlations), using SPSS 22.0, a random $20 \%$ of the observations were independently coded by two coders. Coders were unaware of which observations were used to assess observer agreement.

Parental positive and negative affect. For each period, parental positive and negative affect was coded on a 5-point scale $(1=$ not all positive/negative to $5=$ very positive/negative $)$ based on the System for Coding Interactions in Parent-Child Dyads (SCIPD; Lindahl \& Malik, 1996). Interrater reliability of the parental affect measure was good at all measurement waves: $\alpha>0.76$ for negative parental affect and $\alpha>0.80$ for positive parental affect (see Table 1 for descriptive statistics).

Observed positive and negative parenting behavior. The Dyadic Parent-Child Interaction Coding System was used to code positive and negative parenting behavior during parent-child interactions (Robinson \& Eyberg, 1981; Webster-Stratton, 1989). The scale for positive parenting behavior consisted of 7 items (i.e., acknowledgment, descriptive question, descriptive comment/encouragement, unlabeled praise, labeled praise, positive affect, and physical positive).

Table 1. Descriptives of parental affect and parent and child behavior

\begin{tabular}{|c|c|c|c|c|c|c|c|c|c|c|c|c|}
\hline & \multicolumn{4}{|c|}{ Pretest } & \multicolumn{4}{|c|}{ Posttest } & \multicolumn{4}{|c|}{ Follow-Up } \\
\hline & \multicolumn{2}{|c|}{ Control } & \multicolumn{2}{|c|}{ Intervention } & \multicolumn{2}{|c|}{ Control } & \multicolumn{2}{|c|}{ Intervention } & \multicolumn{2}{|c|}{ Control } & \multicolumn{2}{|c|}{ Intervention } \\
\hline & $M$ & $S D$ & $M$ & $S D$ & $M$ & $S D$ & $M$ & $S D$ & $M$ & $S D$ & $M$ & $S D$ \\
\hline Child negative affectivity & 4.06 & 0.86 & 4.21 & 0.92 & 3.98 & 0.83 & 4.04 & 0.87 & 3.89 & 0.86 & 4.05 & 0.85 \\
\hline Child externalizing behavior & 3.65 & 0.51 & 3.75 & 0.55 & 3.54 & 0.54 & $3.44^{a}$ & 0.53 & 3.42 & 0.55 & $3.37^{b}$ & 0.61 \\
\hline Negative parental affect & 2.05 & 0.70 & 1.94 & 0.68 & 2.04 & 0.71 & 1.94 & 0.64 & 2.07 & 0.67 & 1.96 & 0.72 \\
\hline Positive parental affect & 2.80 & 0.63 & 2.85 & 0.65 & 2.82 & 0.66 & $3.09^{a}$ & 0.64 & 2.85 & 0.64 & $3.05^{b}$ & 0.72 \\
\hline Obs negative parenting & 1.58 & 1.07 & 1.54 & 1.05 & 1.54 & 1.01 & $1.29^{a}$ & 0.86 & 1.53 & 1.08 & 1.41 & 1.01 \\
\hline Obs positive parenting & 2.32 & 0.87 & 2.43 & 0.85 & 2.30 & 0.93 & $2.79^{a}$ & 1.11 & 2.26 & 0.88 & $2.80^{b}$ & 1.21 \\
\hline Rep negative parenting & 2.70 & 0.59 & 2.80 & 0.62 & 2.57 & 0.66 & $2.39^{a}$ & 0.58 & 2.54 & 0.56 & $2.40^{b}$ & 0.56 \\
\hline Rep positive parenting & 4.67 & 0.62 & 4.70 & 0.63 & 4.67 & 0.65 & $4.88^{a}$ & 0.64 & 4.55 & 0.68 & $4.86^{b}$ & 0.66 \\
\hline
\end{tabular}

Note: Obs, observed; Rep, parent reported.

${ }^{a}$ Significantly different from control at posttest, controlling for pretest.

${ }^{b}$ Significantly different from control at follow-up, controlling for pretest. 
The negative parenting behavior scale comprised 6 items (i.e., physical intrusive, physical negative, critical statement, negative command, indirect command without opportunity, direct command without opportunity). Interrater reliability was excellent at all measurement waves; intraclass correlations $>0.96$ for positive parenting behavior and $>0.85$ for negative parenting behavior. The reliability of the parenting scales was acceptable $\alpha>0.60$ for positive parenting and $\alpha>0.67$ for negative parenting (see Table 1 and Table 2 for descriptive statistics).

\section{Questionnaire measures}

Child externalizing problems. The Eyberg Child Behavior Inventory assesses the occurrence of conduct problems in children aged 2 to 16 years (Eyberg, \& Pincus, 1999). The Eyberg Child Behavior Inventory intensity scale consists of 36 items (e.g., "Acts defiant when told to do something"). Parents report how often their child currently engages in each behavior rated on frequency by parents on a 7-point scale $(1=$ never to $7=$ always). Reliability of the scale was good for all three waves ( $\alpha>0.84$; see Table 1 for descriptive statistics).

Negative affectivity. The Children's Behavior Questionnaire-Very Short Form (Putnam \& Rothbart, 2006) assesses primary characteristics of temperament in young children of 3 to 8 years of age. We used the negative affectivity scale as an emotional reactivity measure. The scale was completed by parents and consists of 12 items (e.g., "Gets quite frustrated when prevented from doing something s/he wants to do") that can be answered using a 7-point Likert scale $(1=e x$ tremely untrue for my child to $7=$ extremely true for my child) or with "not applicable." Reliability of the scale was satisfactory ( $\alpha=0.69$; see Table 1 for descriptive statistics). For analyses, child negative affectivity was coded into three groups: low (0: $1 S D$ below the mean, $n=64)$, medium (1: mean $\pm 1 S D, n=258)$ and high (2: $1 S D$ above the mean, $n=64)$.

Reported positive and negative parenting behavior. The Parenting Practice Inventory measures parenting skills and discipline styles of parents with children 6-12 years (WebsterStratton, 2001). The Parenting Practice Inventory was completed by parents and consists of 15 sections, each containing multiple items, which are answered using different scales (e.g., "How likely is it that you respond to this behavior in one of the following ways"). In total, four summary scales were extracted from this questionnaire: harsh and inconsistent discipline (15 items; e.g., "Threatening but not punishing"; $\alpha>0.76$ ), positive verbal discipline (9 items; e.g., "Discussing the problem with the child"; $\alpha>0.71$ ), physical punishment (6 items; e.g., "Slapping or hitting when misbehavior occurs"; $\alpha>0.81$ ), and praise and incentives (11 items; e.g., "Giving a hug or compliment"; $\alpha>0.65)$. Statements about parenting (e.g., "Sometimes one must get very angry with his/ her children to teach them a lesson") were excluded, because we were interested in the actual behavior of parents. Positive parenting behavior was assessed by a combination of the dimensions positive verbal discipline and praise and incentives $(r=.29, p \leq .001)$. Negative parenting behavior was assessed by a combination of the scales harsh and inconsistent discipline and physical punishment $(r=.29, p \leq .001)$. Reliability for both scales was satisfactory on all measurements (positive parenting behavior $\alpha>0.70$; negative parenting behavior $\alpha>0.78$; see Table 1 for descriptive statistics).

\section{Genotyping}

5-HTTLPR. Buccal swabs were collected in lysis buffer (100 $\mathrm{m} M \mathrm{NaCl}, 10 \mathrm{~m} M$ EDTA, $10 \mathrm{~m} M$ Tris $\mathrm{pH} 8,0.1 \mathrm{mg} / \mathrm{ml}$ proteinase, and $0.5 \% \mathrm{w} / \mathrm{v}$ sodium dodecyl sulfate) until further processing. Genomic DNA was isolated from the samples using the Chemagic buccal swab kit on a Chemagen Module I workstation (Chemagen Biopolymer-Technologie AG, Baesweiler, Germany). Within the ORCHIDS study, six genes were analyzed: monoamine oxidase A (MAOA), catechol- $O$-methyltransferase (COMT), dopamine receptors D2 (DRD2) and D4 (DRD4), dopamine active transporter 1 $(D A T 1)$, and 5-HTTLPR. All analyses were automatically performed using specialized genotyping software, after which output of the analysis of each plate was checked by a lab worker. Analyses showing notable deviations or multiple failings were repeated. The output of all analyses was checked by a second lab worker. Each 96-well plate consisted of one blank; analyses were only continued if this blank showed a negative result. To further test reliability of the genotype procedure, duplicate samples of nine children were collected to test the replicability of the results: of the 56 replication genotyping procedures ( $9 \times 6$ genotypes), $53(95 \%)$ were successfully replicated. For one duplicate sample, it was not possible to genotype the MAOA polymorphism. The current paper focuses specifically on the 5-HTTLPR because this polymorphism has been associated with individual differences in emotional reactivity (Hankin et al., 2011; Murphy et al., 2013; Pezawas et al., 2005). The results of the ORCHIDS study with a dopaminergic polygenic score were reported elsewhere (see Chhangur et al., 2016).

The region of interest from the target gene 5-HTT was amplified by polymerase chain reaction (PCR) using the following primers: a FAM-labeled primer $5^{\prime}$-TCCTCCGCTTT GGCGCCTCTTCC-3', and a reverse primer $5^{\prime}$-TGG GGGTTGCAGGGGAGATCCTG-3' ${ }^{\prime}$. Typical PCR reactions contained between 10 and $100 \mathrm{ng}$ genomic DNA template and $10 \mathrm{pmol}$ of forward and reverse primer. PCR was carried out in the presence of 5\% DMSO, $5 \times$ buffer supplied with the enzyme and with $1.25 \mathrm{U}$ of LongAmp Taq DNA Polymerase (NEB) in a total volume of $30 \mu \mathrm{l}$ using the following cycling conditions: initial denaturation step of $10 \mathrm{~min}$ at $95{ }^{\circ} \mathrm{C}$, followed by 26 cycles of $30 \mathrm{~s}$ at $95{ }^{\circ} \mathrm{C}, 30 \mathrm{~s}$ at $69{ }^{\circ} \mathrm{C}, 60 \mathrm{~s}$ at $65{ }^{\circ} \mathrm{C}$, and a final extension step of $10 \mathrm{~min}$ at $65^{\circ} \mathrm{C}$. After PCR $10 \mu \mathrm{l}$ of the sample was subjected to restriction digestion with the enzyme HpaII in a total volume of $20 \mu \mathrm{l}$. 
Table 2. Correlations between study constructs

\begin{tabular}{|c|c|c|c|c|c|c|c|c|c|c|c|c|c|}
\hline & 1 & 2 & 3 & 4 & 5 & 6 & 7 & 8 & 9 & 10 & 11 & 12 & 13 \\
\hline 1. Child sex & - & .01 & -.00 & -.01 & $-.23 * *$ & $-.13 *$ & $-.18 * *$ & -.07 & -.00 & .00 & -.06 & .01 & .06 \\
\hline 2. Child age & - & - & .00 & .01 & .08 & .05 & .07 & .05 & .03 & -.01 & -.04 & $-.14^{*}$ & -.10 \\
\hline 3. Child negtive affectivity & - & - & - & -.03 & $.35^{*}$ & $.23 *$ & $.19 *$ & $-.12 *$ & -.02 & -.08 & -.03 & -.05 & -.02 \\
\hline 4. 5-HTTLPR genotype & - & - & - & - & .06 & .04 & .01 & -.07 & -.00 & -.06 & -.06 & .01 & .06 \\
\hline 5. Externalizing child behavior T1 & - & - & - & - & - & $.62 * *$ & $.53 * *$ & .05 & .03 & .07 & $-.14 * *$ & -.09 & $-.16^{* *}$ \\
\hline 6. Externalizing child behavior T2 & - & - & - & - & - & - & $.70 * *$ & .02 & .06 & .10 & $-.11 *$ & $-.14 * *$ & $-.16^{* *}$ \\
\hline 7. Externalizing child behavior T3 & - & - & - & - & - & - & - & .01 & .03 & $.14 * *$ & -.10 & $-.12 *$ & -.08 \\
\hline 8. Negative parental affect $\mathrm{T} 1$ & - & - & - & - & - & - & - & - & $.21 * *$ & $.33 * *$ & .05 & .07 & -.01 \\
\hline 9. Negative parental affect $\mathrm{T} 2$ & - & - & - & - & - & - & - & - & - & $.32 * *$ & .08 & .09 & .04 \\
\hline 10. Negative parental affect T3 & - & - & - & - & - & - & - & - & - & - & .05 & .06 & $.14 * *$ \\
\hline 11. Positive parental affect $\mathrm{T} 1$ & - & - & - & - & - & - & - & - & - & - & - & $.45^{* *}$ & $.42 * *$ \\
\hline 12. Positive parental affect $\mathrm{T} 2$ & - & - & - & - & - & - & - & - & - & - & - & - & $.45^{*}$ \\
\hline 13. Positive parental affect T3 & - & - & - & - & - & - & - & - & - & - & - & - & - \\
\hline 14. Negative parenting (obs) $\mathrm{T} 1$ & - & - & - & - & - & - & - & - & - & - & - & - & - \\
\hline 15. Negative parenting (obs) $\mathrm{T} 2$ & - & - & - & - & - & - & - & - & - & - & - & - & - \\
\hline 16. Negative parenting (obs) T3 & - & - & - & - & - & - & - & - & - & - & - & - & - \\
\hline 17. Positive parenting (obs) $\mathrm{T} 1$ & - & - & - & - & - & - & - & - & - & - & - & - & - \\
\hline 18. Positive parenting (obs) $\mathrm{T} 2$ & - & - & - & - & - & - & - & - & - & - & - & - & - \\
\hline 19. Positive parenting (obs) T3 & - & - & - & - & - & - & - & - & - & - & - & - & - \\
\hline 20. Negative parenting (rep) $\mathrm{T} 1$ & - & - & - & - & - & - & - & - & - & - & - & - & - \\
\hline 21. Negative parenting (rep) $\mathrm{T} 2$ & - & - & - & - & - & - & - & - & - & - & - & - & - \\
\hline 22. Negative parenting (rep) T3 & - & - & - & - & - & - & - & - & - & - & - & - & - \\
\hline 23. Positive parenting (rep) $\mathrm{T} 1$ & - & - & - & - & - & - & - & - & - & - & - & - & - \\
\hline 24. Positive parenting (rep) T2 & - & - & - & - & - & - & - & - & - & - & - & - & - \\
\hline 25. Positive parenting (rep) T3 & - & - & - & - & - & - & - & - & - & - & - & - & - \\
\hline
\end{tabular}




\begin{tabular}{|c|c|c|c|c|c|c|c|c|c|c|c|c|}
\hline & 14 & 15 & 16 & 17 & 18 & 19 & 20 & 21 & 22 & 23 & 24 & 25 \\
\hline 1. Child sex & -.03 & .00 & .03 & -.03 & -.00 & .01 & -.01 & .01 & .07 & .00 & -.08 & -.09 \\
\hline 2. Child age & $-.17 * *$ & -.08 & $-.16^{* *}$ & $-.12 *$ & $-.20 *$ & $-.20 * *$ & .01 & .06 & .07 & $-.12 *$ & $-.12 *$ & $-.17 *$ \\
\hline 3. Child negtive affectivity & -.03 & .00 & .02 & -.01 & -.02 & -.03 & .08 & .05 & -.00 & $.13 * *$ & .05 & .07 \\
\hline 4. 5-HTTLPR genotype & .05 & $.11 *$ & -.03 & .02 & .03 & .10 & .02 & .01 & .08 & -.06 & .02 & .01 \\
\hline 5. Externalizing child behavior $\mathrm{T} 1$ & $.11 *$ & .06 & $.15^{* *}$ & -.05 & -.06 & -.09 & $.24 * *$ & $.14 * *$ & .09 & .10 & .09 & .06 \\
\hline 6. Externalizing child behavior T2 & $.12 *$ & $.16^{* *}$ & $.16^{* *}$ & -.03 & -.06 & -.09 & .10 & $.18 * *$ & $.28 * *$ & $.12 *$ & .08 & .05 \\
\hline 7. Externalizing child behavior T3 & .04 & .08 & $.12 *$ & -.03 & $-.11 *$ & -.08 & $.15^{* *}$ & $.20 * *$ & $.24 * *$ & .07 & .06 & .08 \\
\hline 8. Negative parental affect $\mathrm{T} 1$ & $.38 * *$ & $.20 * *$ & .09 & -.01 & -.06 & -.06 & -.03 & -.02 & -.01 & -.09 & -.08 & -.10 \\
\hline 9. Negative parental affect $\mathrm{T} 2$ & -.04 & $.44 * *$ & $.37 * *$ & .02 & -.09 & -.05 & -.08 & -.05 & -.05 & .06 & -.07 & -.05 \\
\hline 10. Negative parental affect T3 & $.24 * *$ & .09 & $.48 * *$ & .06 & -.06 & -.01 & -.02 & .04 & .05 & .04 & -.08 & -.06 \\
\hline 11. Positive parental affect $\mathrm{T} 1$ & $-.19 * *$ & -.10 & $-.13 * *$ & $.46 * *$ & $.26 * *$ & $.31 * *$ & $-.16^{* *}$ & -.09 & $-.13 * *$ & -.00 & -.09 & -.08 \\
\hline 12. Positive parental affect $\mathrm{T} 2$ & $-.15 * *$ & $-.16^{* *}$ & -.03 & $.28 * *$ & $.51 * *$ & $.45^{* *}$ & $-.14 * *$ & $-.17 * *$ & $-.12 * *$ & .06 & .02 & .07 \\
\hline 13. Positive parental affect T3 & $-.14 * *$ & $-.11 *$ & -.07 & $.38 * *$ & $.40 * *$ & $.57 * *$ & $-.19 * *$ & $-.19 * *$ & $-.15^{* *}$ & .05 & .03 & .03 \\
\hline 14. Negative parenting (obs) $\mathrm{T} 1$ & - & $.37 * *$ & $.36 * *$ & .05 & $.12 *$ & .02 & $.11 *$ & .10 & .06 & $.18 * *$ & $.16^{* *}$ & $.14 * *$ \\
\hline 15. Negative parenting (obs) $\mathrm{T} 2$ & - & - & $.46^{* *}$ & .03 & .08 & .05 & .04 & .06 & .03 & $.15 * *$ & $.17 * *$ & .09 \\
\hline 16. Negative parenting (obs) $\mathrm{T} 3$ & - & - & - & .08 & .07 & $.11^{*}$ & .07 & .06 & .03 & $.25 * *$ & $.14 * *$ & $.14 * *$ \\
\hline 17. Positive parenting (obs) $\mathrm{T} 1$ & - & - & - & - & $.51 * *$ & $.59 *$ & $-.14 * *$ & $-.12 *$ & $-.13 *$ & $.12 *$ & .07 & $.13 *$ \\
\hline 18. Positive parenting (obs) T2 & - & - & - & - & - & $.67 * *$ & -.08 & -.09 & -.10 & $.18 * *$ & $.22 * *$ & $.21 * *$ \\
\hline 19. Positive parenting (obs) T3 & - & - & - & - & - & - & -.10 & $-.16 * *$ & $-.13 *$ & $.17 * *$ & $.22 * *$ & $.23 * *$ \\
\hline 20. Negative parenting (rep) $\mathrm{T} 1$ & - & - & - & - & - & - & - & $.58 * *$ & $.56^{* *}$ & -.03 & .03 & -.01 \\
\hline 21. Negative parenting (rep) T2 & - & - & - & - & - & - & - & - & $.66^{* *}$ & .03 & -.00 & -.09 \\
\hline 22. Negative parenting (rep) T3 & - & - & - & - & - & - & - & - & - & .00 & -.04 & -.09 \\
\hline 23. Positive parenting (rep) $\mathrm{T} 1$ & - & - & - & - & - & - & - & - & - & - & $.61 * *$ & $.60^{* *}$ \\
\hline 24. Positive parenting (rep) T2 & - & - & - & - & - & - & - & - & - & - & - & $.72 * *$ \\
\hline 25. Positive parenting (rep) T3 & - & - & - & - & - & - & - & - & - & - & - & - \\
\hline
\end{tabular}

Note: T1-T3, Times 1-3.

$* p<.05 . * * p<.01$. 


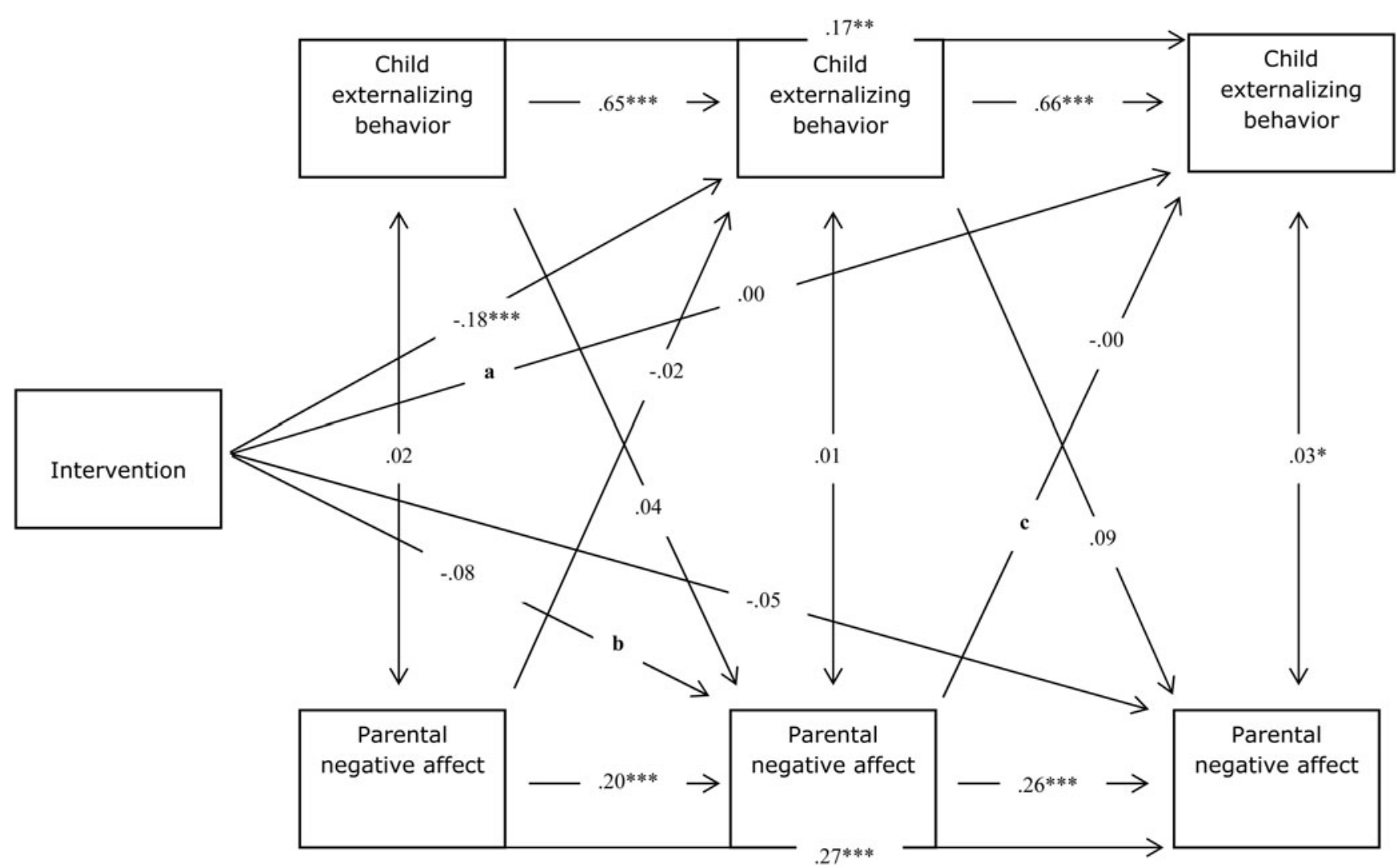

Figure 1. Cross-lagged panel model mediation by parental negative affect. Model fit: $\chi^{2}(N=387,4)=7.02$, comparative fit index $=0.99$, Tucker-Lewis index $=0.97$, root mean square error of approximation $=0.04$.

Restriction was incubated for $2 \mathrm{hr}$ at $37{ }^{\circ} \mathrm{C}$ and inactivated by incubating for $20 \mathrm{~min}$ at $80{ }^{\circ} \mathrm{C}$. One microliter of PCR product before and after restriction was mixed separately with $0.3 \mu \mathrm{l}$ LIZ-500 size standard (Applied Biosystems) and $11.7 \mu \mathrm{l}$ formamide (Applied Biosystems) and run on an Applied Biosystems 3730 genetic analyzer set up for fragment analyses with 50-cm capillaries. Results were analyzed using GeneMarker software (Softgenetics). The genotype distribution was $32.5 \%$ LL genotype, $50.8 \%$ SL genotype, and $16.8 \%$ SS genotype, and did not differ between participants of the control and the intervention condition $\left(\chi^{2}=\right.$ $5.80, d f=2, p=.06$ ). Hardy-Weinberg equilibrium proportions were estimated, and no deviations from these proportions were found $\left(\chi^{2}=0.65, d f=2, p=.72\right.$; Rodriguez, Gaunt, \& Day, 2009). For analyses, 5-HTTLPR genotype was coded into three groups, assuming an additive model (i.e., $0=\mathrm{LL}, 1=\mathrm{SL}, 2=\mathrm{SS}$ ).

\section{Analyses}

We used cross-lagged structural equation models (i.e., CLSEM; Cole \& Maxwell, 2003; Keijsers, 2015; see Figure 1) in Mplus. We used full intention to treat, which means that 44 families in the intervention condition who did not attend any sessions were still included in the analyses. Because the Shapiro-Wilk tests showed that both reported and observed parenting scales were skewed (positively for the negative and negatively for the positive parenting scales), we reported maximum likelihood robust model fit indexes. Model fit was assessed using the root mean square error of approximation (RMSEA; model fit satisfactory when $<0.08$ ) and the comparative fit index (CFI) and the Tucker-Lewis index (TLI; model fit satisfactory when $>0.90 ; \mathrm{Hu} \&$ Bentler, 1999). The analyses were conducted in two steps. First, in order to assess possible mediation of the intervention effect by parental affect and parenting behavior, we used a three-wave CLSEM. We included concurrent (within-time) correlations between the variables, the stability effects for variables (autoregression effects), and longitudinal cross-lagged effects of child behavior and parenting affect or behavior (and vice versa over pretest at Time 1 [T1], posttest at Time 2 [T2], and follow-up at Time 3 [T3]). In this model we tested whether the intervention had a significant effect on child externalizing problems at T3 (Path a, Figure 1), on parental affect or parenting behavior at T2 (Path b, Figure 1), and whether parental affect or parenting behavior at $\mathrm{T} 2$ predicted child externalizing problems at T3 (Path c, Figure 1). For the sake of completeness, we reported all separate paths as part of 
the mediation model. However, significance of all these paths is no requisite for mediation to occur (Zhao, Lynch, \& Chen, 2010). As a formal test of mediation, we included an indirect effect to the model of intervention on child externalizing problems at follow-up via parental affect or parenting behavior at T2 (Path bc, Figure 1). As recommended by Selig and Preacher (2009), a bootstrapping procedure (5,000 bootstrap samples) was used to estimate $95 \%$ confidence intervals (CI) of the indirect effects. Second, in order to test possible moderation by child temperamental negative affectivity and 5-HTTLPR genotype, we repeated the CLSEM with a multigroup approach (SS, SL, and LL genotype; low, average, and high emotionality reactivity).

To test whether the mediation models were significantly different across groups, we used the chi-square difference test $\left(\Delta \chi^{2}\right)$ to compare the models in which all mediation paths were constrained to be equal across groups with the free models in which all mediation paths were estimated freely. Evidence for moderated mediation was found if the constrained model fit significantly worse than the unconstrained model. For the models that indicated significant group differences, we compared the specific path coefficients between the groups, taking into account sample size and standard errors for each group (Cohen, Cohen, West, \& Aiken, 2013; Soper, 2016).

\section{Results}

\section{Preliminary analyses}

Randomization. Participants in the intervention and control condition did not significantly differ on any of the reported demographic variables or pretest scores: age (child or parent), gender (child or parent), country of birth (child or parent), parental education level, work status, marital status, religion, parent-reported and observed parenting behavior, and parent-reported child behavior $(p s>.06)$. Overall, this indicates successful randomization.

Missing data. Our study had high retention rates (92.8\%). In total, 28 families dropped out (23 at posttest, 5 at follow-up). The most common reasons for dropping out were inability to reach parents, (upcoming) divorce of parents, and/or moving house. There was no significant difference between the number of families who dropped out in the intervention and in the control condition ( $p=.19$ ). When comparing parents who

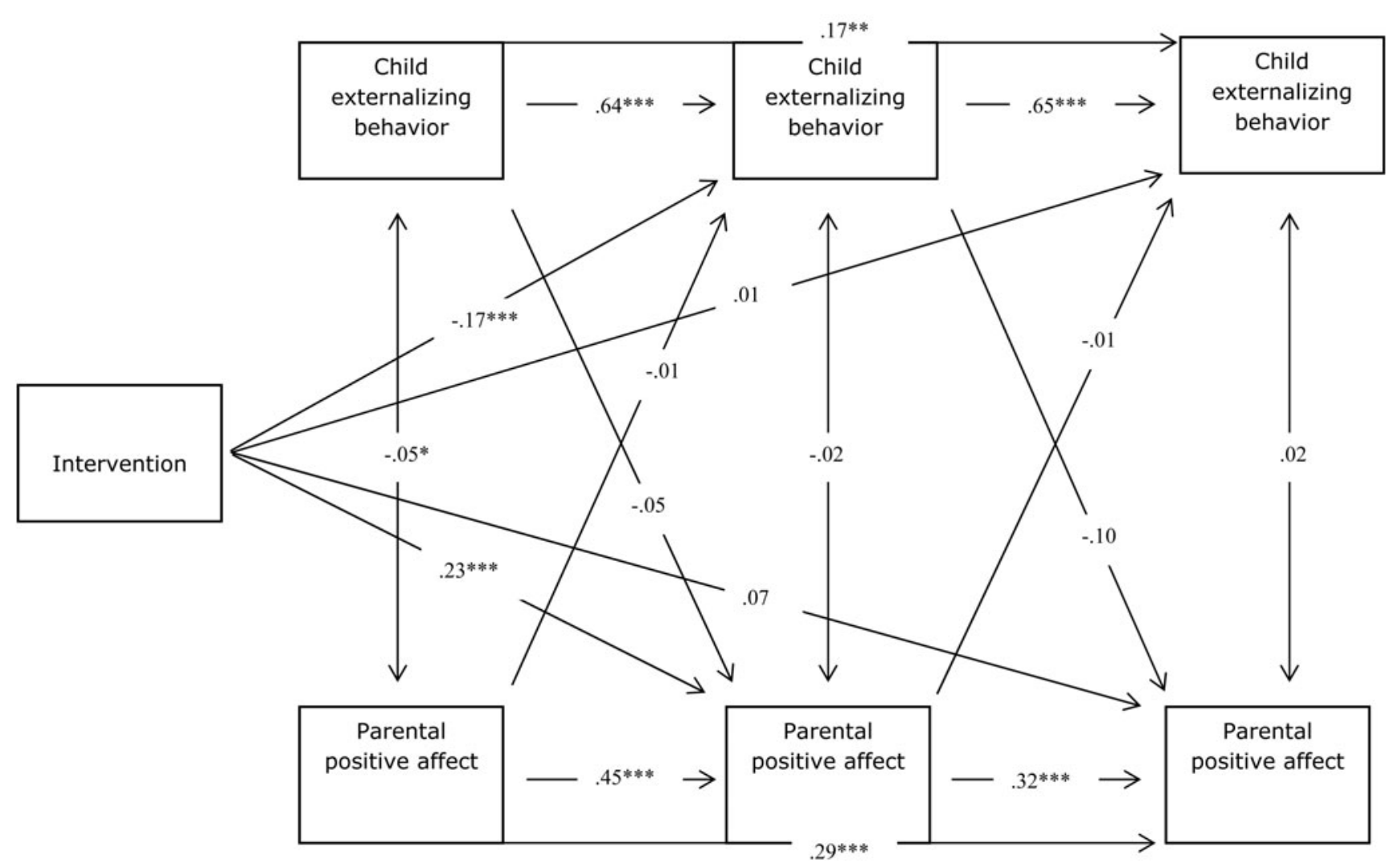

Figure 2. Cross-lagged panel model mediation by parental positive affect. Model fit: $\chi^{2}(N=387,4)=7.17$, comparative fit index $=0.99$, Tucker-Lewis index $=0.98$, root mean square error of approximation $=0.05$. 


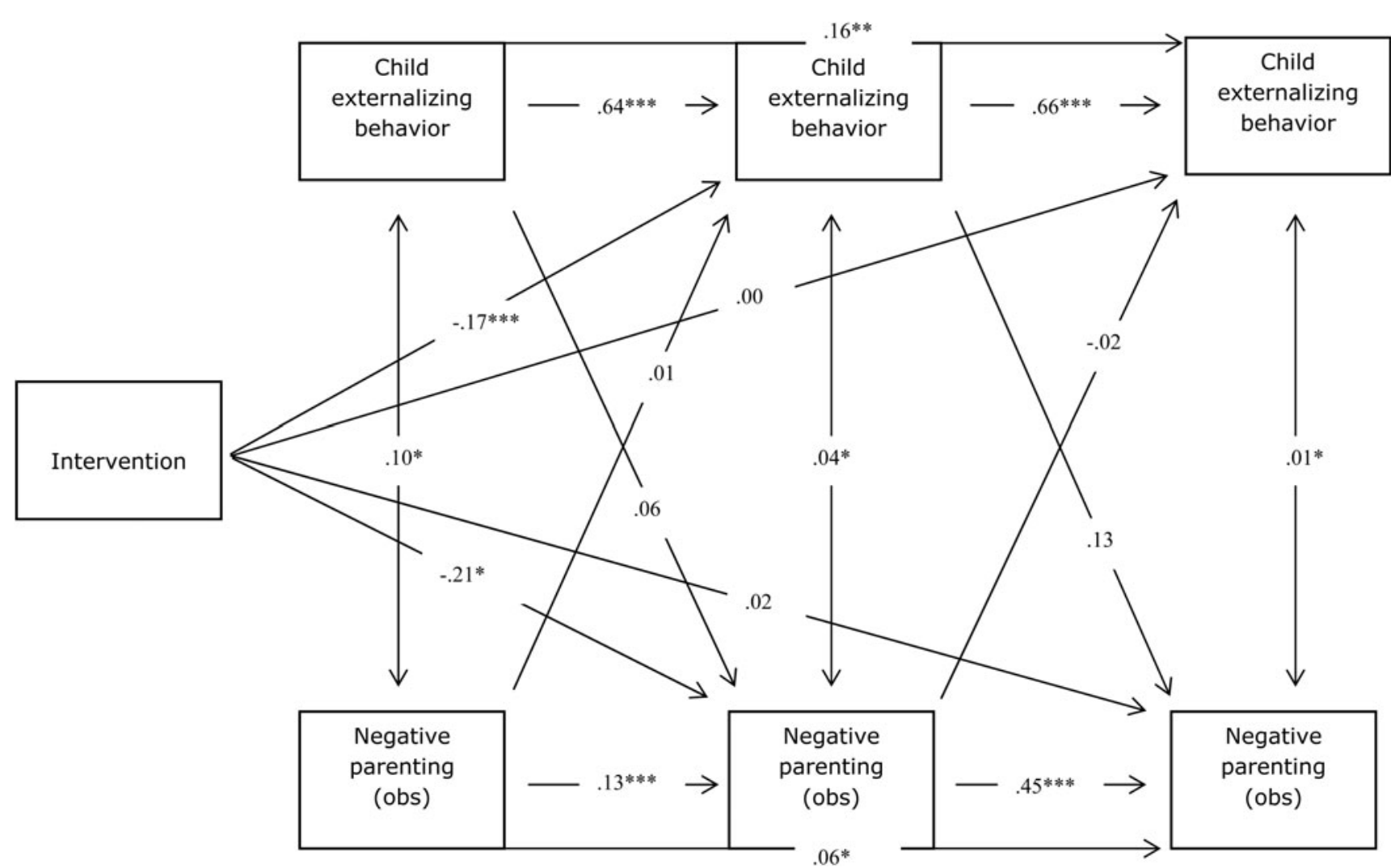

Figure 3. Cross-lagged panel model mediation by observed negative parenting behavior. Model fit: $\chi^{2}(N=387,4)=8.29$, comparative fit index $=0.99$, Tucker-Lewis index $=0.96$, root mean square error of approximation $=0.05$.

participated in all three waves with parents who dropped out at any point, no significant differences were found at pretest scores of reported and observed measurements ( $p \mathrm{~s}>.09$ ). Missing data were handled in Mplus using full information maximum likelihood estimations.

\section{Mechanisms of change: Parental affect}

Inspection of the data showed there were no outliers. Descriptive statistics and correlations for all measures are shown in Tables 1 and 2. See online-only supplementary Tables S.1 and S.2 for correlation tables of all study constructs for the control and intervention condition separate. Both positive and negative parental affect CLSEM yielded excellent fit statistics (Figures 1 and 2). The autoregressive correlations of the models showed that both child externalizing problems and parental negative affect were predicted by the same variable at an earlier time point, indicating that these behaviors were relatively stable over time (T1, T2, T3). Concurrent correlations showed that within-time child externalizing problems and parental negative affect were only weakly correlated at T3 and child externalizing problems and parental positive affect were only weakly correlated at $\mathrm{T} 1$. This indicates that within-time parental affect and child externalizing problems were not structurally related. The main results showed that the intervention was not successful in decreasing child externalizing problems at T3 (Path a, Figures 1 and 2), but was successful in decreasing these problems at T2. In addition, the intervention was successful in increasing parental positive affect (but not decreasing parental negative affect) at T2 (Path b, Figures 1 and 2), but not at T3. However, neither parental negative nor positive affect at $\mathrm{T} 2$ predicted child externalizing problems at T3 (Path c, Figures 1 and 2), and there was no indirect effect from the intervention to child externalizing problems via parental negative or positive affect (Path bc, negative affect: $B=0.000 ; S D=0.004 ; p=.93 ; 95 \%$ CI [-0.004-0.009]; positive affect: $B=-0.003 ; S D=$ $0.008 ; p=.72 ; 95 \%$ CI [ $-0.018-0.009]$. Because previous research indicated that mothers and fathers might differ in their expressed affect (Cassidy, Parke, Butkovsky, \& Braungart, 1992; Chaplin, Cole, \& Zahn-Waxler, 2005), we checked the mean observed scores on positive $\left(M_{\text {fathers }}=2.70\right.$, $\left.S D=0.77 ; M_{\text {mothers }}=2.84, S D=0.62\right)$ and negative $\left(M_{\text {fathers }}=1.88, S D=0.67 ; M_{\text {mothers }}=2.01, S D=0.69\right)$ affect at pretest, but found no significant difference between mothers and fathers in our study, Wilks $\lambda=1.00, F$ $(2,377)=1.03, p=.36$. As a sensitivity check, we also reran the parental affect models excluding fathers $(n=33)$. These 


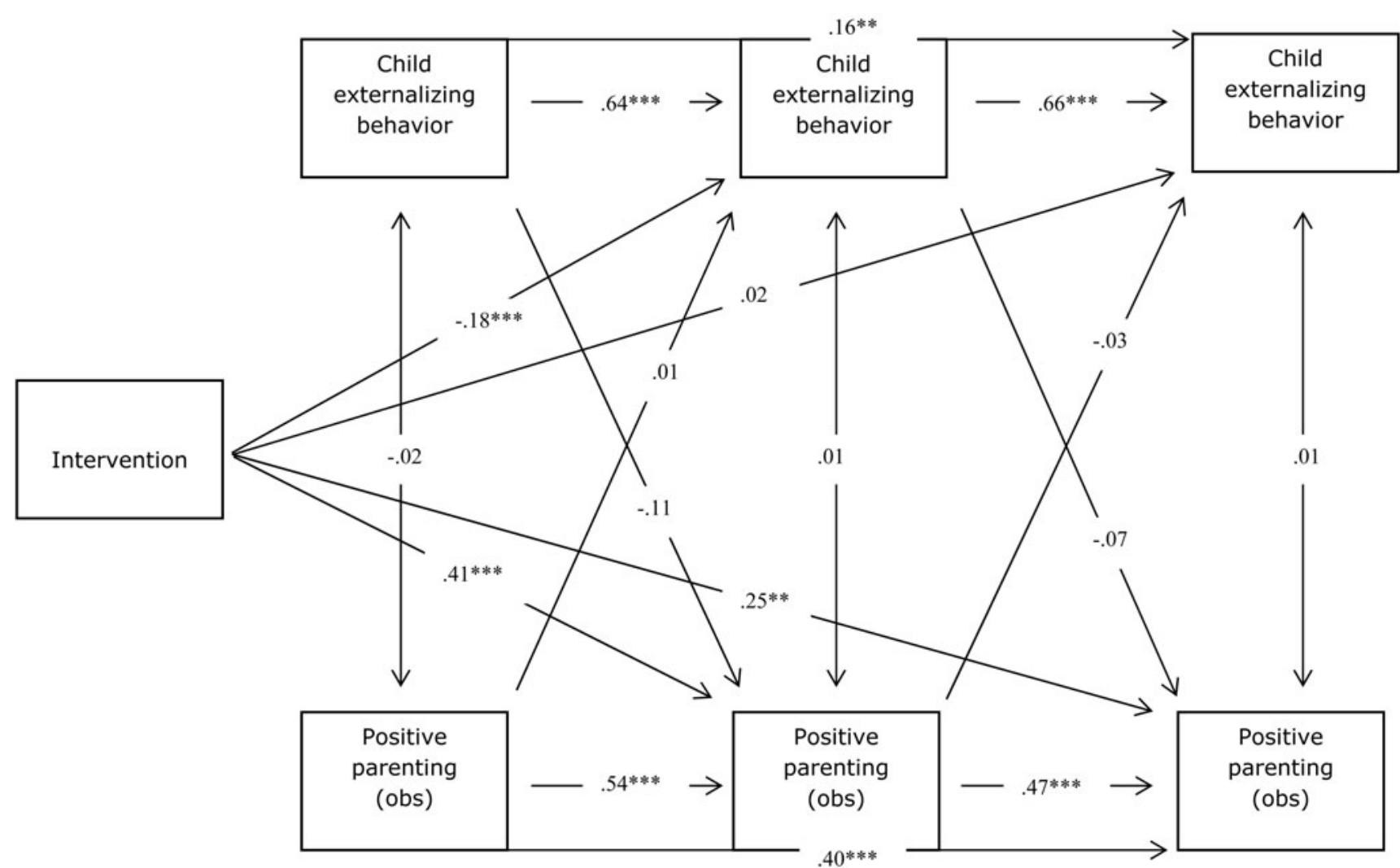

Figure 4. Cross-lagged panel model mediation by observed positive parenting behavior. Model fit: $\chi^{2}(N=387,4)=7.62$, comparative fit index $=1.00$, Tucker-Lewis index $=0.98$, root mean square error of approximation $=0.05$.

models yielded good model fit, and overall the findings remained the same: all direct and indirect effects of maternal affect remained nonsignificant.

\section{Mechanisms of change: Parenting behavior}

All models regarding parenting behavior yielded good model fit statistics (see Figures 3-6). Both child externalizing problems and (negative and positive) parenting behavior were predicted by the same variable at an earlier time point, indicating that these behaviors were stable over time. Child externalizing problems were weakly correlated across all three time points with both observed and reported negative parenting behavior, but were not significantly correlated with observed and reported positive parenting behavior. This indicates that within-time parenting behavior and child externalizing problems were not structurally related.

The main results showed that the intervention was not successful in decreasing child externalizing problems at $\mathrm{T} 3$ (Path a, Figures 3-6), but was successful in decreasing this behavior at T2. In addition, the intervention was successful in reducing observed and reported negative parenting behaviors and increasing observed and reported positive parenting behavior at T2 (Path b, Figures 3-6). Moreover, the intervention was successful in decreasing reported (but not observed) negative parenting behavior and increasing observed and reported positive parenting behavior at T3. However, none of the parenting behavior measures at $\mathrm{T} 2$ predicted child externalizing problems at T3 (Path c, Figures 3-6), and there was no indirect effect from the intervention to child externalizing problems via parenting behavior: Path bc: observed negative parenting: $B=0.005, S D=0.007, p=$ $.50,95 \%$ CI $[-0.004,0.019]$; observed positive parenting: $B=-0.013, S D=0.009, p=.13,95 \%$ CI $[-0.031$, $0.001]$; reported negative parenting: $B=-0.002, S D=$ $0.010, p=.88,95 \%$ CI $[-0.019,0.016]$; reported positive parenting: $B=-0.001, S D=0.010, p=.93 ; 95 \% \mathrm{CI}$ $[-0.019,0.014]$.

\section{Post hoc analysis mediation}

First, CLSEM have been criticized: it has been shown that when constructs in the model are stable over time, the lagged parameters in CLSEM might not represent within-person relationships between constructs over time, but rather betweenperson differences (Hamaker, Kuiper, \& Grasman, 2015). 


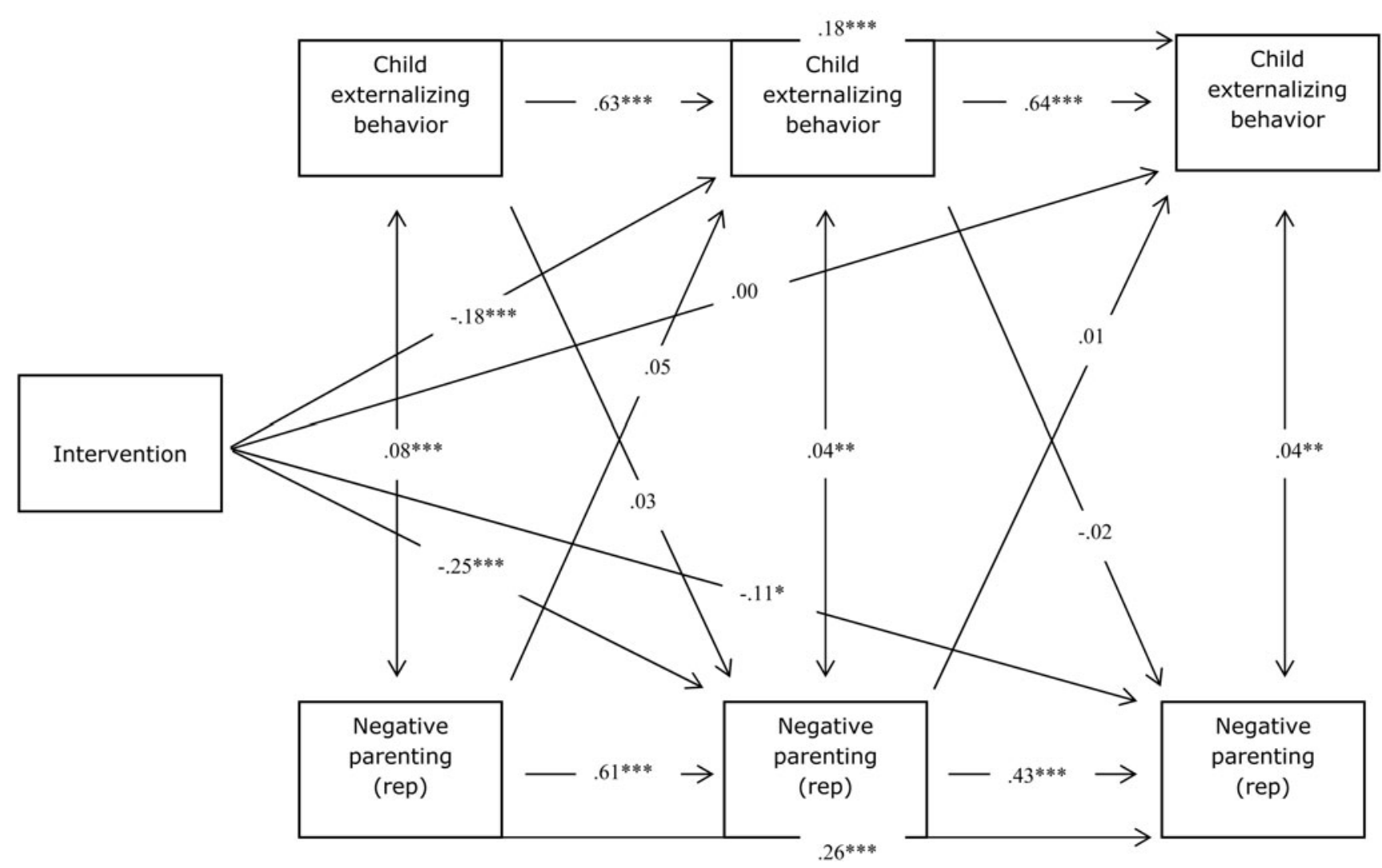

Figure 5. Cross-lagged panel model mediation by reported negative parenting behavior. Model fit: $\chi^{2}(N=387,4)=5.99$, comparative fit index $=1.00$, Tucker-Lewis index $=0.99$, RMSEA $=0.04$.

Therefore, as an additional check of actual within-person relationships between parenting and child externalizing problems, we repeated our analyses using an alternative model that separates the within-person process from stable between-person differences through the inclusion of random intercepts (Hamaker et al., 2015). Overall, these between-person models showed similar results to the "traditional" crosslagged panel models presented above. One notable difference, however, was that the stability of both parent and child externalizing problems over time was less strong or even absent in some models (see online-only supplementary Figures S.1-S.6).

Second, by using the dichotomous variable condition (intervention vs. control) as a predictor in our model (rather than a grouping variable), we force the other estimated pathways to be the same for all families, whether in the control or intervention condition. In order to check whether it is justified to model these pathways for the entire sample, we reran the models while testing whether the crossed pathways (e.g., from parenting at posttest to child behavior at follow-up) significantly differ across conditions. The results showed no differences between conditions on any of the crossed paths (difference scores between -0.164 and $0.153 ; p \mathrm{~s}>.084$ ), indicating it is justified to run one model for the full sample.
See online-only supplementary Tables S.1 and S.2 for correlation tables of all study constructs for the control and intervention conditions separately.

\section{What works for whom: Moderation by child negative affectivity}

Chi-square difference tests of model fit yielded no significant results in any of the mediators (i.e., parent affect or behavior; $\left.\Delta \chi^{2}=22.21-28.82, \Delta d f=18, p s>.05\right)$, indicating that the paths in the mediation models were not significantly different between the three temperament groups (i.e., low, mediate, and high negative affectivity).

\section{What works for whom: Moderation by 5-HTTLPR}

Negative and positive parental affect. A chi-square difference test of model fit yielded a nonsignificant result for the model regarding parental negative affect $\left(\Delta \chi^{2}=27.52, \Delta d f=18, p\right.$ $=.07$ ), indicating that the paths in the mediation model were not significantly different between the three genotype groups (i.e., LL, SL, and SS genotypes). However, we did find a significant chi-square difference for the model regarding parental positive affect $\left(\Delta \chi^{2}=31.48, \Delta d f=18, p=.03\right)$. Results 


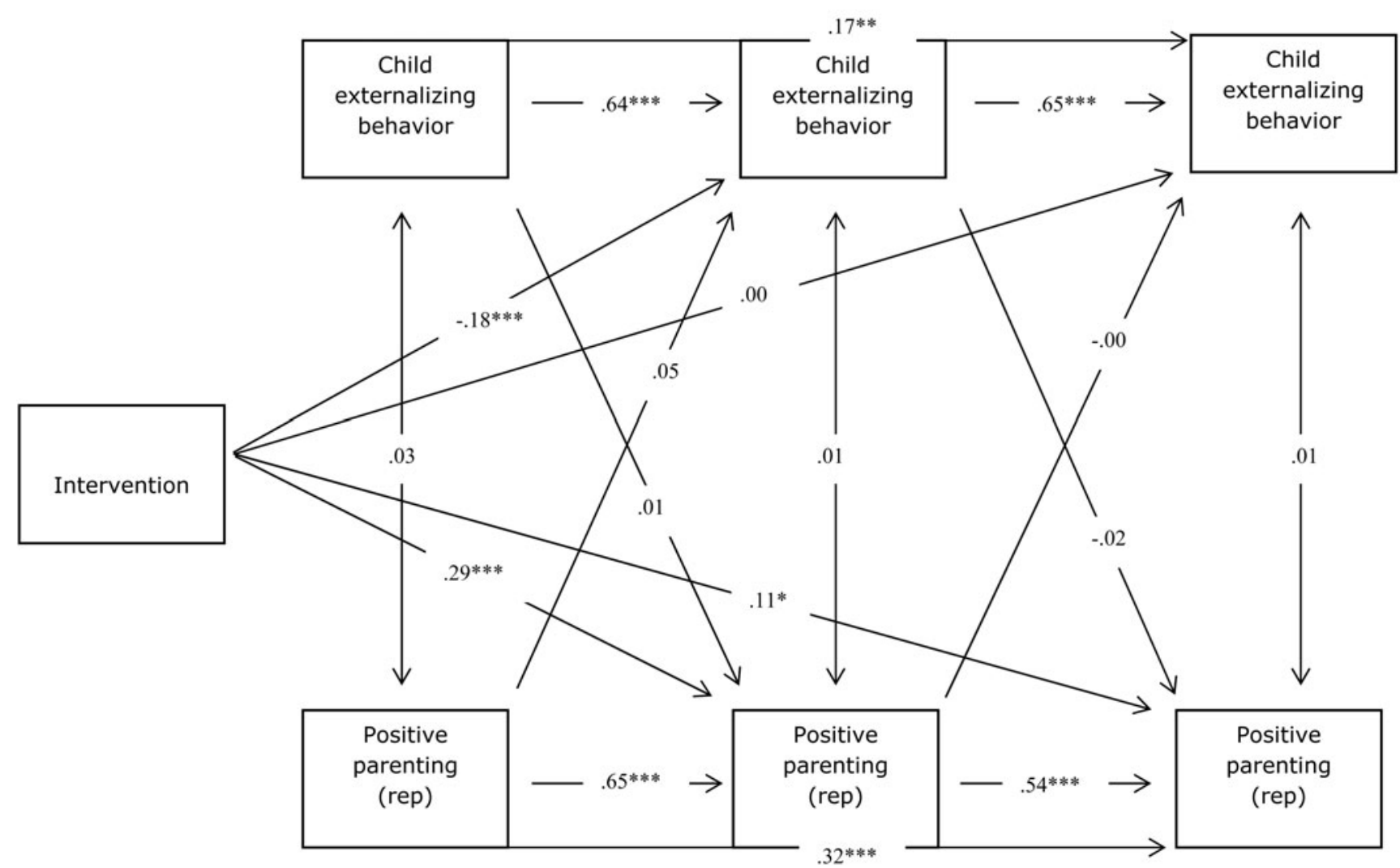

Figure 6. Cross-lagged panel model mediation by reported positive parenting behavior. Model fit: $\chi^{2}(N=387,4)=3.91$, comparative fit index $=1.00$, Tucker-Lewis index $=1.00$, root mean square error of approximation $=0.00, p=.42$.

showed that the intervention did not have a significant effect on child externalizing problems at $\mathrm{T} 3$ in any of the genotype groups (Path a, Table 3). The intervention was only successful in increasing positive parental affect at T2 (Path b, Table 3) for parents of children with the SL genotypes (but not the homozygous groups). However, comparison of the coefficients showed this effect was not significantly larger than for the other groups ( $p \mathrm{~s}>.59$ ). Thus, children's 5-HTTLPR genotype did not significantly moderate the intervention effects on child externalizing problems or parental affect. Moreover, parental positive affect did not predict child externalizing problems in any of the groups (Path c, Table 3), and there was no indirect effect (Path bc, Table 3).

Negative and positive parenting behavior. Chi-square difference tests of model fit yielded a significant result for all parenting behavior models, indicating that the mediation paths were significantly different among the three genotype groups $\left(\Delta \chi^{2}=31.48-38.28, \Delta d f=18, p s<.03\right)$.

The results showed that the intervention did not have a significant effect on child externalizing problems at $\mathrm{T} 3$ in any of the groups (Path a, Tables 4 and 5). The results did show that the intervention was successful in decreasing observed negative parenting and increasing observed positive parenting at T2, but only for parents of short allele carriers (Path b, Table 4). Comparison of the coefficients showed that the effect on observed negative parenting was significantly larger for parents of children with the SS genotype than parents of children with the LL genotype ( $p=.04$, but not significantly larger than parents of children with the SL genotype). However, comparison of the coefficients of observed positive parenting showed that coefficients were not significantly different among the three groups $(p s>.52)$. Thus, children's 5-HTTLPR genotype did significantly moderate the intervention effects on observed negative parenting, but not observed positive parenting. Another interesting finding is that observed positive parenting at $\mathrm{T} 2$ predicted child externalizing problems at T3, but only in the SS group (Path c, see Table 4). For children homozygous for the long allele, there was no significant relation between positive parenting and externalizing problems, whereas for children carrying a short allele, this was a significant, but small, negative relation (significant difference between parents of children homozygous for the short allele and homozygous for the long allele: $p<.05$ ). Thus, only for children homozygous for the short allele higher levels of positive parenting at $\mathrm{T} 2$ were related to lower levels 
Table 3. Results for the moderated mediation pathways observed parental negative and positive affect by 5-HTTLPR genotype

\begin{tabular}{|c|c|c|c|c|c|c|}
\hline Group & Predictor & Outcome & Path & $B$ & $95 \% \mathrm{CI}$ & $p$ \\
\hline \multicolumn{7}{|c|}{ Negative Parental Affect } \\
\hline \multirow[t]{4}{*}{ LL } & Intervention & Child externalizing problems $\mathrm{T} 3$ & $\mathrm{a}$ & $0.01(0.08)$ & & .93 \\
\hline & Intervention & Parental negative affect $\mathrm{T} 2$ & $\mathrm{~b}$ & $-0.02(0.12)$ & & .87 \\
\hline & Parental negative affect $\mathrm{T} 2$ & Child externalizing problems $\mathrm{T} 3$ & $\mathrm{c}$ & $-0.05(0.06)$ & & .39 \\
\hline & Intervention via parental negative affect $\mathrm{T} 2$ & Child externalizing problems $\mathrm{T} 3$ & bc & $0.00(0.01)$ & {$[-0.01,0.02]$} & .92 \\
\hline \multirow[t]{4}{*}{ SL } & Intervention & Child externalizing problems $\mathrm{T} 3$ & $\mathrm{a}$ & $-0.02(0.06)$ & & .77 \\
\hline & Intervention & Parental negative affect $\mathrm{T} 2$ & $\mathrm{~b}$ & $-0.01(0.11)$ & & .91 \\
\hline & Parental negative affect $\mathrm{T} 2$ & Child externalizing problems $\mathrm{T} 3$ & $\mathrm{c}$ & $-0.03(0.05)$ & & .53 \\
\hline & Intervention via parental negative affect $\mathrm{T} 2$ & Child externalizing problems $\mathrm{T} 3$ & $\mathrm{bc}$ & $0.00(0.01)$ & {$[-0.01,0.02]$} & .95 \\
\hline \multirow[t]{4}{*}{ SS } & Intervention & Child externalizing problems T3 & $\mathrm{a}$ & $0.17(0.10)$ & & .09 \\
\hline & Intervention & Parental negative affect $\mathrm{T} 2$ & $\mathrm{~b}$ & $0.15(0.07)$ & & .02 \\
\hline & Parental negative affect $\mathrm{T} 2$ & Child externalizing problems $\mathrm{T} 3$ & $\mathrm{c}$ & $-0.38(0.16)$ & & .03 \\
\hline & Intervention via parental negative affect $\mathrm{T} 2$ & Child externalizing problems $\mathrm{T} 3$ & bc & $-0.06(0.04)$ & {$[-0.17,-0.01]$} & .17 \\
\hline \multicolumn{7}{|c|}{ Positive Parental Affect } \\
\hline \multirow[t]{4}{*}{ LL } & Intervention & Child externalizing problems T3 & a & $-0.01(0.08)$ & & .91 \\
\hline & Intervention & Parental positive affect T2 & $\mathrm{b}$ & $0.18(0.11)$ & & .11 \\
\hline & Parental positive affect $\mathrm{T} 2$ & Child externalizing problems $\mathrm{T} 3$ & $\mathrm{c}$ & $0.10(0.06)$ & & .08 \\
\hline & Intervention via parental positive affect $\mathrm{T} 2$ & Child externalizing problems T3 & $\mathrm{bc}$ & $0.02(0.02)$ & {$[-0.00,0.06]$} & .29 \\
\hline \multirow[t]{4}{*}{ SL } & Intervention & Child externalizing problems T3 & $\mathrm{a}$ & $-0.01(0.07)$ & & .90 \\
\hline & Intervention & Parental positive affect T2 & $\mathrm{b}$ & $0.24(0.09)$ & & .01 \\
\hline & Parental positive affect $\mathrm{T} 2$ & Child externalizing problems $\mathrm{T} 3$ & $\mathrm{c}$ & $-0.03(0.05)$ & & .52 \\
\hline & Intervention via parental positive affect $\mathrm{T} 2$ & Child externalizing problems $\mathrm{T} 3$ & $\mathrm{bc}$ & $-0.01(0.01)$ & {$[-0.03,0.01]$} & .55 \\
\hline \multirow[t]{4}{*}{ SS } & Intervention & Child externalizing problems $\mathrm{T} 3$ & $\mathrm{a}$ & $0.15(0.12)$ & & .18 \\
\hline & Intervention & Parental positive affect T2 & $\mathrm{b}$ & $0.28(0.15)$ & & .06 \\
\hline & Parental positive affect $\mathrm{T} 2$ & Child externalizing problems $\mathrm{T} 3$ & $\mathrm{c}$ & $-0.18(0.12)$ & & .16 \\
\hline & Intervention via parental positive affect $\mathrm{T} 2$ & Child externalizing problems T3 & $\mathrm{bc}$ & $-0.05(0.05)$ & {$[-0.19,0.00]$} & .37 \\
\hline
\end{tabular}

Note: Model fit: observed negative affect: $\chi^{2}(N=387,12)=11.37$, comparative fit index $=1.00$, Tucker-Lewis index $=1.00$, root mean square error of approximation $=0.00, p=.50$; observed positive affect: $\chi^{2}(N=387,12)=25.33$, comparative fit index $=0.98$, Tucker-Lewis index $=0.89$, root mean square error of approximation $=0.09$. LL, long-long allele; SL, short-long allele; SS, short-short allele; T3, Time 3; T2, Time 2.

of child externalizing problems at $\mathrm{T} 3$. There was however no indirect effect, for any of the genotype groups (Path bc, Table 4).

In contrast to the effects on observed parenting behavior, the results showed that the intervention was only successful in decreasing reported negative and increasing reported positive parenting behavior at $\mathrm{T} 2$ in parents of long allele carriers (Path b, Table 5). Comparison of the coefficients of reported negative parenting showed that this effect was significantly larger for parents of children homozygous for the long allele compared to parents of children homozygous for the short allele $(p=.04)$ but not compared to parents of heterozygous children. Comparison of the coefficients of reported positive parenting showed that the effect for parents was not significantly larger than in the other groups ( $p$ s $>.14)$. Thus, children's 5-HTTLPR genotype did significantly moderate the intervention effects on reported negative parenting, but not reported positive parenting. However, reported parenting behavior did not predict child externalizing problems (Path c, Table 5), and there was no indirect effect, for any of the genotype groups (Path bc, Table 5).

\section{Discussion}

In a randomized controlled trial $(N=387)$ we tested whether the intervention effects of the behavioral parent training IY on child externalizing problems were explained by changes in parental affect and parenting behavior. Furthermore, we tested whether these mechanisms of change were more important in some families than in others due to children's temperamental negative affectivity or 5-HTTLPR genotype. Our results showed that IY was effective in decreasing parent-reported child externalizing problems, specifically at posttest. In addition, the IY intervention was effective in increasing observed parental positive affect (but not in reducing negative affect), reported and observed positive parenting, and reducing observed and reported negative parenting behavior at posttest. Furthermore, the intervention was successful in reducing reported negative parenting, and increasing reported and observed positive parenting behavior at 10-month follow-up. Our findings on the intervention effects are in line with many previous studies showing effectiveness of IY (for a meta-analysis see Menting et al., 2013). 
Table 4. Results for the moderated mediation pathways observed negative and positive parenting by 5-HTTLPR genotype

\begin{tabular}{|c|c|c|c|c|c|c|}
\hline Group & Predictor & Outcome & Path & $B$ & $95 \% \mathrm{CI}$ & $p$ \\
\hline \multicolumn{7}{|c|}{ Observed Negative Parenting Behavior } \\
\hline \multirow[t]{4}{*}{ LL } & Intervention & Child externalizing problems T3 & a & $0.01(0.08)$ & & .92 \\
\hline & Intervention & Negative parenting T2 & $\mathrm{b}$ & $-0.06(0.14)$ & & .67 \\
\hline & Negative parenting T2 & Child externalizing problems T3 & $\mathrm{c}$ & $0.02(0.05)$ & & .72 \\
\hline & Intervention via Negative parenting $\mathrm{T} 2$ & Child externalizing problems T3 & $\mathrm{bc}$ & $-0.00(0.01)$ & {$[-0.02,0.01]$} & .89 \\
\hline \multirow[t]{4}{*}{ SL } & Intervention & Child externalizing problems T3 & $\mathrm{a}$ & $-0.02(0.06)$ & & .75 \\
\hline & Intervention & Negative parenting $\mathrm{T} 2$ & $\mathrm{~b}$ & $-0.26(0.15)$ & & .08 \\
\hline & Negative parenting T2 & Child externalizing problems T3 & $\mathrm{c}$ & $-0.02(0.04)$ & & .64 \\
\hline & Intervention via negative parenting $\mathrm{T} 2$ & Child externalizing problems T3 & $\mathrm{bc}$ & $0.00(0.01)$ & {$[-0.01,0.03]$} & .69 \\
\hline \multirow[t]{4}{*}{ SS } & Intervention & Child externalizing problems T3 & $\mathrm{a}$ & $0.09(0.12)$ & & .44 \\
\hline & Intervention & Negative parenting T2 & $\mathrm{b}$ & $-0.59(0.26)$ & & .02 \\
\hline & Negative parenting T2 & Child externalizing problems T3 & $\mathrm{c}$ & $-0.04(0.08)$ & & .66 \\
\hline & Intervention via negative parenting $\mathrm{T} 2$ & Child externalizing problems T3 & $\mathrm{bc}$ & $0.02(0.05)$ & {$[-0.04,0.14]$} & .68 \\
\hline \multicolumn{7}{|c|}{ Observed Positive Parenting Behavior } \\
\hline \multirow[t]{4}{*}{ LL } & Intervention & Child externalizing problems $\mathrm{T} 3$ & $\mathrm{a}$ & $-0.00(0.08)$ & & .98 \\
\hline & Intervention & Positive parenting T2 & $\mathrm{b}$ & $0.31(0.16)$ & & .05 \\
\hline & Positive parenting $\mathrm{T} 2$ & Child externalizing problems T3 & $\mathrm{c}$ & $0.02(0.03)$ & & .51 \\
\hline & Intervention via positive parenting $\mathrm{T} 2$ & Child externalizing problems T3 & $\mathrm{bc}$ & $0.01(0.01)$ & {$[-0.01,0.03]$} & .56 \\
\hline \multirow[t]{4}{*}{ SL } & Intervention & Child externalizing problems T3 & $\mathrm{a}$ & $0.00(0.06)$ & & .95 \\
\hline & Intervention & Positive parenting T2 & $\mathrm{b}$ & $0.44(0.13)$ & & .00 \\
\hline & Positive parenting $\mathrm{T} 2$ & Child externalizing problems T3 & $\mathrm{c}$ & $-0.04(0.04)$ & & .28 \\
\hline & Intervention via positive parenting $\mathrm{T} 2$ & Child externalizing problems T3 & $\mathrm{bc}$ & $-0.02(0.02)$ & {$[-0.05,0.00]$} & .32 \\
\hline \multirow[t]{4}{*}{ SS } & Intervention & Child externalizing problems T3 & $\mathrm{a}$ & $0.14(0.10)$ & & .16 \\
\hline & Intervention & Positive parenting T2 & $\mathrm{b}$ & $0.49(0.24)$ & & .04 \\
\hline & Positive parenting T2 & Child externalizing problems $\mathrm{T} 3$ & $\mathrm{c}$ & $-0.08(0.04)$ & & .05 \\
\hline & Intervention via positive parenting $\mathrm{T} 2$ & Child externalizing problems T3 & $\mathrm{bc}$ & $-0.04(0.03)$ & {$[-0.11,-0.01]$} & .15 \\
\hline
\end{tabular}

Note: Model fit: observed negative parenting: $\chi^{2}(N=387,12)=12.57$, comparative fit index $=1.00$, Tucker-Lewis index $=1.00$, root mean square error of approximation $=0.02$; observed positive parenting: $\chi^{2}(N=387,12)=12.19$ comparative fit index $=1.00$, Tucker-Lewis index $=1.00$, root mean square error of approximation $=0.01$. LL, long-long allele; SL, short-long allele; SS, short-short allele; T3, Time 3; T2, Time 2.

It was interesting that the results made clear that the intervention effects on child externalizing problems and the effects on parental affect and parenting behavior were unrelated. Although this is in contrast to our expectations, lack of support for parenting as a mechanism of change underlying BPT effects on child externalizing problems is not unique (Forehand et al., 2014). The majority of mediation tests in BPT studies have yielded nonsignificant results (i.e., 55\% of tests discussed by Forehand et al., 2014). Our findings add to the claim that, to date, we seemingly cannot provide an empirically supported explanation for how even our most effective and well-studied interventions produce change (Forehand et al., 2014; Kazdin, 2007). Differences in findings between previous studies that did report significant mediation by parenting of BPT effects on child externalizing behavior and our study might also be partly explained by methodological differences. Specifically, unlike many previous studies, we employed a highly stringent test, using different informants (i.e., parent reports and observational data) at different time points (i.e., immediate posttest and follow-up), for the mediator (i.e., parental affect and parenting behavior) and outcome (i.e., child externalizing problems). Some of the earlier significant findings on parenting as a mediator of BPT might be explained by codependency of the mediator and outcome measures.

The IY intervention produced significant effects on parenting and child behavior that were unrelated, which indicates that the changes in parenting and child behavior are parallel, but independent processes (see also Weeland et al., 2017). Perhaps, this phenomenon can be explained by a third unmeasured factor. It has been found that BPT programs have "beneficial side effects," for example, by decreasing parent and family distress, and increasing quality of life and perceived self-efficacy in parents (Feldman \& Werner, 2002). This might be specifically the case for interventions such as IY because they use a collaborative approach aiming to empower parents. The group meetings might cause parents to relabel oppositional behavior as more common and less problematic, and to feel empowered by sharing experiences and being handed tools for dealing with this behavior.

We also did not find that parental affect or parenting behavior were more important mechanisms of change in explaining the effectiveness of IY for some children more than others due to their negative affectivity or 5-HTTLPR genotype. Although theoretically these two markers could be related, our study showed neither a correlation nor similar mod- 
Table 5. Results moderated mediation pathways reported negative and positive parenting by 5-HTTLPR genotype

\begin{tabular}{|c|c|c|c|c|c|c|}
\hline Group & Predictor & Outcome & Path & $B$ & $95 \% \mathrm{CI}$ & $p$ \\
\hline \multicolumn{7}{|c|}{ Reported Negative Parenting Behavior } \\
\hline \multirow[t]{4}{*}{ LL } & Intervention & Child externalizing problems T3 & $\mathrm{a}$ & $-0.0100(.08)$ & & .88 \\
\hline & Intervention & Negative parenting $\mathrm{T} 2$ & $\mathrm{~b}$ & $-0.46(0.09)$ & & .00 \\
\hline & Negative parenting $\mathrm{T} 2$ & Child externalizing problems $\mathrm{T} 3$ & $\mathrm{c}$ & $-0.05(0.07)$ & & .44 \\
\hline & Intervention via negative parenting $\mathrm{T} 2$ & Child externalizing problems $\mathrm{T} 3$ & bc & $0.02(0.03)$ & {$[-0.03,0.02]$} & .46 \\
\hline \multirow[t]{4}{*}{ SL } & Intervention & Child externalizing problems T3 & $\mathrm{a}$ & $-0.02(0.06)$ & & .79 \\
\hline & Intervention & Negative parenting $\mathrm{T} 2$ & $\mathrm{~b}$ & $-0.18(0.08)$ & & .02 \\
\hline & Negative parenting $\mathrm{T} 2$ & Child externalizing problems $\mathrm{T} 3$ & $\mathrm{c}$ & $0.01(0.06)$ & & .89 \\
\hline & Intervention via negative parenting $\mathrm{T} 2$ & Child externalizing problems $\mathrm{T} 3$ & bc & $-0.00(0.01)$ & {$[-0.03,-0.00]$} & .90 \\
\hline \multirow[t]{4}{*}{ SS } & Intervention & Child externalizing problems T3 & $\mathrm{a}$ & $0.13(0.10)$ & & .21 \\
\hline & Intervention & Negative parenting T2 & $\mathrm{b}$ & $-0.06(0.13)$ & & .64 \\
\hline & Negative parenting $\mathrm{T} 2$ & Child externalizing problems $\mathrm{T} 3$ & $\mathrm{c}$ & $0.14(0.10)$ & & .17 \\
\hline & Intervention via negative parenting $\mathrm{T} 2$ & Child externalizing problems $\mathrm{T} 3$ & $\mathrm{bc}$ & $-0.01(0.02)$ & {$[-0.09,-0.01]$} & .71 \\
\hline \multicolumn{7}{|c|}{ Reported Positive Parenting Behavior } \\
\hline \multirow[t]{4}{*}{ LL } & Intervention & Child externalizing problems T3 & $\mathrm{a}$ & $-0.00(0.08)$ & & .96 \\
\hline & Intervention & Positive parenting $\mathrm{T} 2$ & $\mathrm{~b}$ & $0.34(0.10)$ & & .00 \\
\hline & Positive parenting T2 & Child externalizing problems $\mathrm{T} 3$ & $\mathrm{c}$ & $0.02(0.06)$ & & .68 \\
\hline & Intervention via positive parenting $\mathrm{T} 2$ & Child externalizing problems $\mathrm{T} 3$ & bc & $0.01(0.01)$ & {$[-0.02,0.04]$} & .69 \\
\hline \multirow[t]{4}{*}{ SL } & Intervention & Child externalizing problems $\mathrm{T} 3$ & $\mathrm{a}$ & $-0.03(0.06)$ & & .62 \\
\hline & Intervention & Positive parenting T2 & $\mathrm{b}$ & $0.30(0.07)$ & & .00 \\
\hline & Positive parenting T2 & Child externalizing problems $\mathrm{T} 3$ & $\mathrm{c}$ & $0.04(0.04)$ & & .38 \\
\hline & Intervention via positive parenting $\mathrm{T} 2$ & Child externalizing problems T3 & $\mathrm{bc}$ & $0.01(0.02)$ & {$[-0.01,0.03]$} & .41 \\
\hline \multirow[t]{4}{*}{ SS } & Intervention & Child externalizing problems T3 & $\mathrm{a}$ & $0.13(0.10)$ & & .21 \\
\hline & Intervention & Positive parenting $\mathrm{T} 2$ & $\mathrm{~b}$ & $0.11(0.13)$ & & .40 \\
\hline & Positive parenting $\mathrm{T} 2$ & Child externalizing problems $\mathrm{T} 3$ & $\mathrm{c}$ & $-0.16(0.12)$ & & .18 \\
\hline & Intervention via positive parenting $\mathrm{T} 2$ & Child externalizing problems T3 & $\mathrm{bc}$ & $-0.02(0.03)$ & {$[-0.07,0.03]$} & .53 \\
\hline
\end{tabular}

Note: Model fit: reported negative parenting behavior: $\chi^{2}(N=387,12)=13.51, \mathrm{CFI}=1.00$, Tucker-Lewis index $=0.99$, root mean square error of approximation $=0.03$; reported positive parenting behavior: $\chi^{2}(N=387,12)=8.57$, comparative fit index $=1.00$, Tucker-Lewis index $=1.00$, root mean square error of approximation $=0.00, p=.74$.

eration patterns between child negative affectivity and 5 HTTLPR genotype. This contrasts with earlier findings from Auerbach et al. (1999), who demonstrated that infants homozygous for the 5-HTTLPR short allele scored higher on negative emotionality than infants carrying the long allele. However, to our knowledge, this finding has not been replicated in school-aged children. Moreover, studies using related constructs such as fear and anger responses, as well as temperamental and observed emotional reactivity, found no associations with the 5-HTTLPR genotype (Auerbach et al., 2001; Dragan \& Oniszczenko, 2005; Weeland, Slagt, et al., 2015)

Our analyses did show other, unexpected, moderation findings: children's 5-HTTLPR genotype significantly moderated intervention effectiveness on parenting behavior, as well as the relation between observed positive parenting and child externalizing problems. Intervention effects on observed and reported negative parenting behavior, but not on parental affect or positive parenting behavior, were significantly moderated by children's 5-HTTLPR genotype. This might indicate that some parents are more susceptible to the IY program than others. A possible explanation for this finding might lie in the bidirectional relation between parent and child behavior. Actual changes in parenting behavior after intervention might be not only formed during the intervention sessions but also informed and shaped over time by the reciprocal influences between parent and child behavior (Sameroff, 2000). Children's different reactions to intervention-induced changes in parenting behavior might serve as a feedback mechanism for further changes in parenting behavior. For example, when parents see that the use of certain parenting techniques works really well on their children, they might further increase the use of these techniques, whether they might stop using techniques that initially evoke resistance. Different families possibly need different support when it comes to intervening in the development of externalizing problems, due to children's differential reactions to specific parenting strategies, possibly related to their 5-HTTLPR genotype. Given that children and parents share genes, it is also possible that child genotype is a marker for parent genotype, with some parents being genetically more susceptible to intervention effects than others.

It was interesting that different moderation patterns were found for observed and reported parenting behavior outcomes. On the one hand, this might indicate that this gene- 
based moderation of intervention effects is not highly robust and replicable. On the other hand, this might show that moderation effects are very specific and differ between outcomes using different reporters or instruments. Findings on the role of the 5-HTTLPR in externalizing problems have been mixed, in that both short and long allele carriers have been shown to be more susceptible to environmental predictors of these problems (for a review, see Weeland, Overbeek, et al., 2015). These heterogeneous findings might partly be explained by differences between studies in conceptualization and measurement of the outcome variable (Heininga, Oldehinkel, Veenstra, \& Nederhof, 2015; Weeland, Overbeek, et al., 2015).

The results indicated that parents of children homozygous for the long allele reported the largest decrease in negative parenting at posttest. However, compared to parents of short allele carriers, these parents showed lower observed decreases in negative parenting during the parent-child interactions at posttest. This might indicate that parents of children carrying two long alleles are more prone to report improvements, whereas they show less actual changes in their behavior, compared to parents of children carrying two short alleles. It might be that, although families of children with the LL genotype experience the biggest relief in parenting stress and/ or the biggest increase in the feeling of empowerment directly after the intervention (and therefore report a larger decrease in negative parenting), these families are also the first to fall back on old patterns of negative parent-child interactions, due to certain child characteristics (and therefore show a smaller decrease in negative parenting). For example, these children might be less responsive to certain parenting techniques addressed in the BPT interventions (see Hankin et al., 2011), leading to parental frustration. This relates to another interesting finding of our study. Our results suggest that in both the intervention and control groups, observed positive parenting was only a significant predictor of child externalizing problems for SS genotypes. This effect was very small and was not replicated in any of the other parenting outcome measures. Nevertheless, this might indicate that children carrying the long allele are less susceptible to specifically positive parenting behavior than children homozygous for the short allele.

Our results have to be interpreted in light of some limitations. First of all, we focused on the 5-HTTLPR polymorphism as a candidate for genetic moderation because it has been related to differences in negative affect and reactivity to emotional stimuli. This relation might, however, be explained by individual differences in serotonin availability, which depends not only on variation in expression of the 5-HTTLPR but also on variation in synthesis, reuptake, and degradation. Future research could take into account multiple genetic markers, for example, by assessing a serotonergic genetic pathway (e.g., Bralten et al., 2013). A second important limitation of this study is the modest sample size in relation to the complexity of the statistical models tested. Although our sample is relatively large for a BPT RCT (a recent meta-anal- ysis on IY showed an average sample size of 95; see Menting et al., 2013), the tested models of mediation and moderation contained many parameter estimations. Perhaps this explains that in our moderation results several "trend findings" occurred, findings that just fail to reach significance, which might indicate lack of power to find similar effects in the groups with a smaller $n$. Therefore, testing these models within a larger sample might have yielded different results. Another and related issue is the increased possibility of chance findings (Type I errors) when estimating multiple models containing multiple pathways. Needless to say, our results have to be interpreted with caution and need to be replicated in an independent sample.

Furthermore, as with most intervention studies, our recruitment procedure resulted in a select sample of Dutch, relatively high socioeconomic status families, and our results might not be generalizable to the general population or other countries. In addition, as in most BPT studies, our study sample mostly consisted of mothers. Including fathers in BPT programs comes with specific challenges (Salinas, Smith, \& Armstrong, 2011). As a result, we know little about the effectiveness of such programs for fathers (Isaacs, Webb, Jerome, \& Fabiano, 2015). Future research on BPT should encourage paternal participation in parent training and examine effectiveness of the intervention for fathers separately. Finally, intervention effects of IY were most pronounced at posttest, which reduced power for testing differential effects of IY on child externalizing problems at follow-up via changes in parenting behavior at posttest. Although significance of all these paths is no statistical requisite for the full mechanism of change to occur (Zhao et al., 2010), nonsignificant paths do reduce power to find significant effects of the overall mechanism of change. It would be interesting to see whether changes in parenting behavior or affect during the intervention might explain changes in child behavior at posttest. Future research could explore the effects of changes in parenting between pretest and posttest (through increasing the number of measurement waves) and whether this gives us more insight into the mechanisms of change. Our findings regarding mediation and moderation are complex and highlight that very large and well-powered samples are needed to adequately resolve the ambiguities in previous BPT literature regarding both mechanisms of change and moderation by child temperament and genotype.

Notwithstanding these limitations, our study contributes to the current literature in a number of important ways. First, testing a specific theory-driven hypothesis on mediation and moderation has enabled us to specify our research strategies accordingly. This specificity not only increases replicability of the study but also prevents a "black box effect": knowing what goes in and what comes out, but not knowing the process in between. Using specific hypotheses enabled us to confirm or reject specific assumptions on mediation and moderation, increasing our understanding of the specific processes involved. Second, using an RCT to test this theory enabled us to draw conclusions about causal effects of the intervention and change mechanisms on child externalizing 
problems and to rule out alternative explanations for moderation effects, such as correlations between environment and child characteristics. As such, it is a robust approach for testing possible Gene $\times$ Environment in externalizing problems. Third, we used observed and reported measures of parenting behavior. This is important as most previous mediation analyses relied on parent report of both parenting and child externalizing problems, possibly causing inflated observed associations due to shared informant variance. Our analyses showed that reported and observed parenting were only weakly related, indicating they measure different things. In addition, we found different moderation effects using observed and reported parenting behavior. Furthermore, by measuring the mediator at posttest and outcome at followup we were able to take into account the timeline of the mediation processes (Kazdin, 2007).

Taking into account mediators (i.e., what works) and moderators (i.e., for whom) of intervention effects is of both scientific and clinical importance. From a scientific perspective, insight into differential effects of specific mechanisms of change can help us gain insight into differential causal pathways leading to externalizing problems (Tolan, Dodge, \& Rutter, 2013). It will teach us not only which children might be more susceptible to their environment or changes therein but also to what specific environmental factors they are more susceptible. From a clinical perspective, information on what works for whom might be used to tailor interventions (Chorpita et al., 2007). However, it is unclear if and how information on genetic moderation should be implemented in clinical practice. Using genetic information to identify children who might be more or less susceptible for a certain intervention is costly, invasive, and yields ethical concerns (Chhangur, Weeland, Matthys, \& Overbeek, 2015; Ross, Saal, David, Anderson, \& the American Association of Pediatrics, 2013). Genetic screening may have negative side effects, such as alterations in self-image and expectations by self and others or changes in parental perception of the child (e.g., false deterministic claims about child externalizing problems). As a less problematic alternative, knowledge of behavioral (rather than genetic) markers may help us in identifying with greater ease those children for whom a specific intervention is suitable, and for whom different or additional care may be more effective (see Gardner et al., 2006). In our study, temperamental negative affectivity was not a significant moderator of intervention effectiveness. Future research may explore other behavioral markers, such as emotion regulation skills or reward and punishment sensitivity.

\section{Conclusion}

In conclusion, our study showed that IY was successful in reducing both observed and reported negative parenting behavior and increasing parental positive affect as well as observed and reported positive parenting behavior at posttest. It was important that these effects did not explain the IY intervention effects on child externalizing problems. This calls for future intervention studies to take into account alternative mechanisms of change such as decreases in parenting stress and improved quality of life or perceived parental self-efficacy. Furthermore, our results show that effects of BPT programs may depend on child genotype; in our case, the 5 HTTLPR genotype was identified as a moderator of intervention effects on negative parenting behavior. Overall, these finding might indicate that in research on BPT, the question "what works for which parents" could be an important one to further explore.

\section{Supplementary Material}

To view the supplementary material for this article, please visit https://doi.org/10.1017/S0954579417000499.

\section{References}

Albert, D., Belsky, D. W., Crowley, D. M., Bates, J. E., Pettit, G. S., Lansford, J. E., . . Dodge, K. A. (2015). Developmental mediation of genetic variation in response to the Fast Track prevention program. Development and Psychopathology, 27, 81-95.

Auerbach, F. M., Ebstein, R., Kahana, M., \& Levine, J. (2001). The association of the dopamine D4 receptor gene (DRD4) and the serotonin transporter promoter gene (5-HTTLPR) with temperament in 12-month-old Infants. Journal of Child Psychology and Psychiatry, 42, 777-783. doi:10.1017/S0021963001007612

Auerbach, J., Geller, V., Lezer, S., Shinwell, E., Belmaker, R. H., Levine, J., \& Ebstein, R. P. (1999). Dopamine D4 receptor (D4DR) and serotonin transporter promoter (5-HTTLPR) polymorphisms in the determination of temperament in 2-month-old infants. Molecular Psychiatry, 4, 369373. doi: $10.1038 /$ sj.mp.4000531

Bakermans-Kranenburg, M. J., van IJzendoorn, M. H., Pijlman, F. T. A., Mesman, J., \& Juffer, F. (2008). Experimental evidence for differential susceptibility: Dopamine D4 receptor polymorphism (DRD4 VNTR) moderates intervention effects on toddlers' externalizing behavior in a randomized controlled trial. Developmental Psychology, 44, 293-300. doi:10.1037/0012-1649.44.1.293
Belsky, J., Hsieh, K. H., \& Crnic, K. A. (1998). Mothering, fathering, and infant negativity as antecedents of boys' externalizing problems and inhibition at age 3 years: Differential susceptibility to rearing experience? Development and Psychopathology, 10, 301-319. Retrieved from http://journals.cambridge.org/abstract_S095457949800162X

Belsky, J., \& Pluess, M. (2009). Beyond diathesis stress: Differential susceptibility to environmental influences. Psychological Bulletin, 135, 885908. doi:10.1037/a0017376

Bradley, R. H., \& Corwyn, R. F. (2008). Infant temperament, parenting, and externalizing behavior in first grade: A test of the differential susceptibility hypothesis. Journal of Child Psychology and Psychiatry, and Allied Disciplines, 49, 124-131. doi:10.1111/j.1469-7610.2007.01829.x

Bralten, J., Franke, B., Waldman, I., Rommelse, N., Hartman, C., Asherson, P., . . Arias-Vásquez, A. (2013). Candidate genetic pathways for attention-deficit/hyperactivity disorder (ADHD) show association to hyperactive/impulsive symptoms in children with ADHD. Journal of the American Academy of Child \& Adolescent Psychiatry, 52, 1204-1212. doi:10.1016/j.jaac.2013.08.020

Cassidy, J., Parke, R. D., Butkovsky, L., \& Braungart, J. M. (1992). Familypeer connections: The roles of emotional expressiveness within the fam- 
ily and children's understanding of emotions. Child Development, 63, 603-618. doi:10.2307/1131349

Chaplin, T. M., Cole, P. M., \& Zahn-Waxler, C. (2005). Parental socialization of emotion expression: Gender differences and relations to child adjustment. Emotion, 5, 80-88. doi:10.1037/1528-3542.5.1.80

Chhangur, R. R., Weeland, J., Matthys, W., \& Overbeek, G. (2015). Gene by environment research to prevent externalizing problem behavior: Ethical questions raised from a public healthcare perspective. Public Health Ethics. Advance online publication. doi:10.1093/phe/phv024

Chhangur, R. R., Weeland, J., Overbeek, G., Matthys, W., Castro, B., Giessen, D., \& Belsky, J. (2016). Genetic moderation of intervention efficacy: Dopaminergic genes, the Incredible Years, and externalizing behavior in children. Child Development. Advanced online publication. doi:10.1111/ cdev. 12612

Chhangur, R. R., Weeland, J., Overbeek, G., Matthys, W., \& Orobio de Castro, B. (2012). ORCHIDS: An observational randomized controlled trial on childhood differential susceptibility. BMC Public Health, 12, e917. doi:10.1186/1471-2458-12-917

Chorpita, B. F., Becker, K. D., \& Daleiden, E. L. (2007). Understanding the common elements of evidence-based practice: Misconceptions and clinical examples. Journal of the American Academy of Child \& Adolescent Psychiatry, 46, 647-652. doi:10.1097/chi.0b013e318033ff71

Cohen, J., Cohen, P., West, S. G., \& Aiken, L. S. (2013). Applied multiple regression/correlation analysis for the behavioral sciences (3rd ed.). Mahwah, NJ: Erlbaum.

Cole, D. A., \& Maxwell, S. E. (2003). Testing mediational models with longitudinal data: Questions and tips in the use of structural equation modeling. Journal of Abnormal Psychology, 112, 558-577.

Coplan, R. J., Hastings, P. D., Lagacé-Séguin, D. G., \& Moulton, C. E. (2002). Authoritative and authoritarian mothers' parenting goals, attributions, and emotions across different childrearing contexts. Parenting, 2, 1-26. doi:10.1207/S15327922PAR0201_1

Crandall, A., Deater-Deckard, K., \& Riley, A. W. (2015). Maternal emotion and cognitive control capacities and parenting: A conceptual framework. Developmental Review, 36, 105-126. doi:10.1016/j.dr.2015.01.004

Davies, P. T., \& Cicchetti, D. (2013). How and why does the 5-HTTLPR gene moderate associations between maternal unresponsiveness and children's disruptive problems? Child Development, 85, 484-500. doi:10. 1111/cdev. 12148

Derryberry, D., \& Rothbart, M. K. (1988). Arousal, affect, and attention as components of temperament. Journal of Personality and Social Psychology, 55, 958 .

Dix, T. (1991). The affective organization of parenting: Adaptive and maladaptative processes. Psychological Bulletin, 110, 3-25.

Dragan, W. Ł., \& Oniszczenko, W. (2005). Polymorphisms in the serotonin transporter gene and their relationship to two temperamental traits measured by the formal characteristics of behavior-temperament inventory: Activity and emotional reactivity. Neuropsychobiology, 51, 269-274. doi: 10.1159/000085823

Duncombe, M. E., Havighurst, S. S., Holland, K. A., \& Frankling, E. J. (2012). The contribution of parenting practices and parent emotion factors in children at risk for disruptive behavior disorders. Child Psychiatry and Human Development, 43, 715-733. doi:10.1007/s10578012-0290-5

Durlak, J. A., \& DuPre, E. P. (2008). Implementation matters: A review of research on the influence of implementation on program outcomes and the factors affecting implementation. American Journal of Community Psychology, 41, 327-350. doi:10.1007/s10464-008-9165-0

Eyberg, S. M., \& Pincus, D. (1999). Eyberg Child Behavior Inventory and Sutter-Eyberg Student Behavior Inventory—Revised: Professional manual. Lutz, FL: Psychological Assessment Resources.

Feldman, M. A., \& Werner, S. E. (2002). Collateral effects of behavioral parent training on families of children with developmental disabilities and behavior disorders. Behavioral Interventions, 17, 75-83. doi:10.1002/ bin. 111

Forehand, R., Lafko, N., Parent, J., \& Burt, K. B. (2014). Is parenting the mediator of change in behavioral parent training for externalizing problems of youth? Clinical Psychology Review, 34, 608-619. doi:10.1016/ j.cpr.2014.10.001

Gallitto, E. (2015). Temperament as a moderator of the effects of parenting on children's behavior. Development and Psychopathology, 27, 257-273.

Gardner, F., Burton, J., \& Klimes, I. (2006). Randomised controlled trial of a parenting intervention in the voluntary sector for reducing child conduct problems: Outcomes and mechanisms of change. Journal of Child Psy- chology and Psychiatry, and Allied Disciplines, 47, 1123-1132. doi:10.1111/j.1469-7610.2006.01668.x

Gyurak, A., Haase, C. M., Sze, J., Goodkind, M. S., Coppola, G., Lane, J., . . Levenson, R. W. (2013). The effect of the serotonin transporter polymorphism (5-HTTLPR) on empathic and self-conscious emotional reactivity. Emotion, 13, 25-35.

Hamaker, E. L., Kuiper, R. M., \& Grasman, R. P. (2015). A critique of the cross-lagged panel model. Psychological Methods, 21, 102-116.

Hanisch, C., Hautmann, C., Plück, J., Eichelberger, I., \& Döpfner, M. (2014). The prevention program for externalizing problem behavior (PEP) improves child behavior by reducing negative parenting: Analysis of mediating processes in a randomized controlled trial. Journal of Child Psychology and Psychiatry, 55, 473-484. doi:10.1111/jcpp.12177

Hankin, B. L., Nederhof, E., Oppenheimer, C. W., Jenness, J., Young, J. F., Abela, J. R. Z., . . . Oldehinkel, A. J. (2011). Differential susceptibility in youth: Evidence that 5-HTTLPR $\times$ Positive Parenting is associated with positive affect "for better and worse." Translational Psychiatry, 1, e44. doi:10.1038/tp.2011.44

Heininga, V., Oldehinkel, A., Veenstra, R., \& Nederhof, E. (2015). I just ran a thousand analyses: Benefits of multiple testing in understanding equivocal evidence on gene-environment interactions. PIOS ONE, 10, e01.

Hu, L., \& Bentler, P. M. (1999). Cutoff criteria for fit indexes in covariance structure analysis: Conventional criteria versus new alternatives. Structural Equation Modeling, 6, 1-55. doi:10.1080/10705519909540118

Isaacs, L., Webb, A., Jerome, S., \& Fabiano, G. (2015). Inclusion and engagement of fathers in behavioral parent training for ADHD: An update and recommendations. ADHD Report, 23, 1-7. doi:10.1521/adhd.2015. 23.8.1

Isley, S. L., O'Neil, R., Clatfelter, D., \& Parke, R. D. (1999). Parent and child expressed affect and children's social competence: Modeling direct and indirect pathways. Developmental Psychology, 35, 547-560.

Kaminski, J. W., Valle, L. A., Filene, J. H., \& Boyle, C. L. (2008). A metaanalytic review of components associated with parent training program effectiveness. Journal of Abnormal Child Psychology, 36, 567-589. doi:10.1007/s10802-007-9201-9

Karreman, A., van Tuijl, C., van Aken, M. A. G., \& Deković, M. (2006). Parenting and self-regulation in preschoolers: A meta-analysis. Infant and Child Development, 15, 561-579.

Kazdin, A. E. (2007). Mediators and mechanisms of change in psychotherapy research. Annual Review of Clinical Psychology, 3, 1-27. doi:10.1146/ annurev.clinpsy.3.022806.091432

Keijsers, L. (2015). Parental monitoring and adolescent problem behaviors: How much do we really know? International Journal of Behavioral Development. Advance online publication. doi:10.1177/0165025415592515

Kret, M. E., Denollet, J., Grèzes, J., \& de Gelder, B. (2011). The role of negative affectivity and social inhibition in perceiving social threat: An fMRI study. Neuropsychologia, 49, 1187-1193. doi:10.1016/j.neuropsy chologia.2011.02.007

Leijten, P., Raaijmakers, M. A. J., Orobio de Castro, B., \& Matthys, W. (2013). Does socioeconomic status matter? A meta-analysis on parent training effectiveness for disruptive child behavior. Journal of Clinical Child and Adolescent Psychology, 42, 384-392. doi:10.1080/15374416. 2013.769169

Lindahl, K. M., \& Malik, N. M. (1996). System for Coding Interactions in Parent-Child Dyads (SCIPD): A coding system for structured and unstructured parent-child tasks. Coral Gables, FL: University of Miami, Department of Psychology.

Lipscomb, S. T., Leve, L. D., Shaw, D. S., Neiderhiser, J. M., Scaramella, L. V, Ge, X., ... Reiss, D. (2012). Negative emotionality and externalizing problems in toddlerhood: Overreactive parenting as a moderator of genetic influences. Development and Psychopathology, 24, 167-179. doi:10.1017/S0954579411000757

Martin, S. E., Clements, M. L., \& Crnic, K. A. (2002). Maternal emotions during mother-toddler interaction: Parenting in affective context. Parenting: Science and Practice, 2, 105-126. Retrieved from http://www.tandfonline. com.proxy.library.uu.nl/doi/abs/10.1207/S15327922PAR0202_02

McCart, M. R., Priester, P. E., Davies, W. H., \& Azen, R. (2006). Differential effectiveness of behavioral parent-training and cognitive-behavioral therapy for antisocial youth: A meta-analysis. Journal of Abnormal Child Psychology, 34, 525-541. doi:10.1007/s10802-006-9031-1

Menting, A. T., Orobio de Castro, B., \& Matthys, W. (2013). Effectiveness of the Incredible Years parent training to modify disruptive and prosocial child behavior: A meta-analytic review. Clinical Psychology Review, 33, 901-913. doi:10.1016/j.cpr.2013.07.006 
Morris, A. S., Silk, J. S., Steinberg, L., Sessa, F. M., Avenevoli, S., \& Essex, M. J. (2002). Temperamental vulnerability and negative parenting as interacting predictors of child adjustment. Journal of Marriage and Family, 64, 461-471. doi:10.1111/j.1741-3737.2002.00461.x

Murphy, S. E., Norbury, R., Godlewska, B. R., Cowen, P. J., Mannie, Z. M., Harmer, C. J., \& Munafò, M. R. (2013). The effect of the serotonin transporter polymorphism (5-HTTLPR) on amygdala function: A meta-analysis. Molecular Psychiatry, 18, 512-520. doi:10.1038/mp.2012.19

Pezawas, L., Meyer-Lindenberg, A., Drabant, E. M., Verchinski, B. A., Munoz, K. E., Kolachana, B. S., . . . Weinberger, D. R. (2005). 5-HTTLPR polymorphism impacts human cingulate-amygdala interactions: A genetic susceptibility mechanism for depression. Nature Neuroscience, 8 , 828-834. doi:10.1038/nn1463

Putnam, S. P., \& Rothbart, M. K. (2006). Development of short and very short forms of the Children's Behavior Questionnaire. Journal of Personality Assessment, 87, 102-112. doi:10.1207/s15327752jpa8701_09

Ramos, M. C., Guerin, D. W., Gottfried, A. W., Bathurst, K., \& Oliver, P. H. (2005). Family conflict and children's behavior problems: The moderating role of child temperament. Structural Equation Modeling, 12, 278298. doi:10.1207/s15328007sem1202_6

Robinson, E. A., \& Eyberg, S. M. (1981). The dyadic parent-child interaction coding system: Standardization and validation. Journal of Consulting and Clinical Psychology, 49, 245-250. doi:10.1037/0022-006X.49. 2.245

Rodriguez, S., Gaunt, T. R., \& Day, I. N. (2009). Hardy-Weinberg equilibrium testing of biological ascertainment for Mendelian randomization studies. American Journal of Epidemiology, 169, 505-514. doi:10.1093/ aje/kwn359

Ross, L. F., Saal, H. M., David, K. L., Anderson, R. R., \& American Academy of Pediatrics. (2013). Technical report: Ethical and policy issues in genetic testing and screening of children. Genetics in Medicine, 15, 234245 .

Rothbaum, F., \& Weisz, J. R. (1994). Parental caregiving and child externalizing behavior in nonclinical samples: A meta-analysis. Psychological Bulletin, 116, 55-74. doi:10.1037/0033-2909.116.1.55

Rudy, D., \& Grusec, J. E. (2006). Authoritarian parenting in individualist and collectivist groups: Associations with maternal emotion and cognition and children's self-esteem. Journal of Family Psychology, 20, 68-78. doi:10.1037/0893-3200.20.1.68

Rueger, S. Y., Katz, R. L., Risser, H. J., \& Lovejoy, M. C. (2011). Relations between parental affect and parenting behaviors: A meta-analytic review. Parenting: Science and Practice, 11, 1-33. doi:10.1080/15295192.2011. 539503

Salinas, A., Smith, J. C., \& Armstrong, K. (2011). Engaging fathers in behavioral parent training: Listening to fathers' voices. Journal of Pediatric Nursing, 26, 304-311. doi:10.1016/j.pedn.2010.01.008

Sameroff, J. A. (2000). Developmental systems and psychopathology. Development and Psychopathology, 12, 297-312. Retrieved from http:/l journals.cambridge.org/abstract_S0954579400003035

Sandler, I. N., Schoenfelder, E. N., Wolchik, S. A., \& MacKinnon, D. P. (2011). Long-term impact of prevention programs to promote effective parenting: Lasting effects but uncertain processes. Annual Review of Psychology, 62, 299-329. doi:10.1146/annurev.psych.121208. 131619
Scott, S., \& O'Connor, T. G. (2012). An experimental test of differential susceptibility to parenting among emotionally-dysregulated children in a randomized controlled trial for oppositional behavior. Journal of Child Psychology and Psychiatry, 53, 1184-1193.

Selig, J. P., \& Preacher, K. J. (2009). Mediation models for longitudinal data in developmental research. Research in Human Development, 6, 144 164. doi:10.1080/15427600902911247

Soper, D. S. (2016). Significance of the difference between two slopes calculator [Computer software]. Retrieved from http://www.danielsoper.com/ statcalc

Tolan, P. H., Dodge, K., \& Ruter, M. (2013). Tracking the multiple pathways of parent and family influence on disruptive behaviour disorders. In P. H. Tolan \& B. L. Leventhal (Eds.), Disruptive behaviour disorders (pp. 161-191). New York: Springer.

Van den Hoofdakker, B. J., Nauta, M. H., Dijck-Brouwer, D. A., van der Veen-Mulders, L., Sytema, S., Emmelkamp, P. M. G., . . . Hoekstra, P. J. (2012). Dopamine transporter gene moderates response to behavioral parent training in children with ADHD: A pilot study. Developmental Psychology, 48, 567-574. doi:10.1037/a0026564

van IJzendoorn, M. H., Belsky, J., \& Bakermans-Kranenburg, M. J. (2012). Serotonin transporter genotype 5HTTLPR as a marker of differential susceptibility \& quest: A meta-analysis of child and adolescent gene-byenvironment studies. Translational Psychiatry, 2, e147. doi:10.1038/ tp. 2012.73

Van Zeijl, J., Mesman, J., Stolk, M. N., Alink, L. R. A., van IJzendoorn, M. H., Bakermans-Kranenburg, M. J., . . Koot, H. M. (2007). Differential susceptibility to discipline: The moderating effect of child temperament on the association between maternal discipline and early childhood externalizing problems. Journal of Family Psychology, 21, 626-636. doi:10.1037/0893-3200.21.4.626

Webster-Stratton, C. (1989). The relationship of marital support, conflict, and divorce to parent perceptions, behaviors, and childhood conduct problems. Journal of Marriage and Family, 51, 417-430.

Webster-Stratton, C. (2001). Parenting Practices Interview. Unpublished manuscript.

Webster-Stratton, C. (2008). The Incredible Years: Parents, teachers, and children training series. Residential Treatment for Children \& Youth, 18, 31-45. doi:10.1300/J007v18n03_04

Weeland, J., Chhangur, R. R., van der Giessen, D., Matthys, W., Orobio de Castro, B., \& Overbeek, G. (2017). Intervention effectiveness of The Incredible Years: New insights into sociodemographic and intervention-based moderators. Behavior Therapy, 48, 1-18. doi:10.1016/j.beth.2016.08.002

Weeland, J., Overbeek, G., Orobio de Castro, B., \& Matthys, W. (2015). Underlying mechanisms of gene-environment interactions in externalizing behavior: A systematic review and search for theoretical mechanisms. Clinical Child and Family Psychology Review, 18, 413-442. doi:10. 1007/s10567-015-0196-4

Weeland, J., Slagt, M., Brummelman, E., Matthys, W., Orobio de Castro, B., \& Overbeek, G. (2015). 5-HTTLPR expression outside the skin: An experimental test of the emotional reactivity hypothesis in children. PLOS ONE, 10, e0141474. doi:10.1371/journal.pone.0141474

Zhao, X., Lynch, J. G., \& Chen, Q. (2010). Reconsidering Baron and Kenny: Myths and truths about mediation analysis. Journal of Consumer Research, 37, 197-206. doi:10.1086/651257 